Article

\title{
Bacillus simplex-A Little Known PGPB with Anti-Fungal Activity-Alters Pea Legume Root Architecture and Nodule Morphology When Coinoculated with Rhizobium leguminosarum bv. viciae
}

Allison R. Schwartz ${ }^{1, \dagger}$, Irma Ortiz ${ }^{1, \dagger}$, Maskit Maymon ${ }^{1}$, Craig W. Herbold ${ }^{2}$, Nancy A. Fujishige ${ }^{1}$, Janahan A. Vijanderan ${ }^{3}$, William Villella ${ }^{3}$, Kayoko Hanamoto ${ }^{1}$, Andrew Diener ${ }^{1}$, Erin R. Sanders ${ }^{3}$, Darleen A. DeMason ${ }^{4}$, and Ann M. Hirsch ${ }^{1,5, *}$

1 Department of Molecular, Cell and Developmental Biology, University of California, Los Angeles, CA 90095-1606, USA; E-Mails: allison.r.schwartz@gmail.com (A.R.S.); iorti003@ucr.edu (I.O.); maskit@ucla.edu (M.M.); nancy.fuji@gmail.com (N.A.F.); kay.hanamoto@gmail.com (K.H.); diener@lifesci.ucla.edu (A.D.)

2 School of Biological Sciences, University of Waikato, Hamilton 3240, New Zealand; E-Mail: cherbold@waikato.ac.nz

3 Department of Microbiology, Immunology and Molecular Genetics, University of California, Los Angeles, CA 90095-1489, USA; E-Mails: jovonh127@gmail.com (J.A.V.);

willvillella@yahoo.com (W.V.); erins@microbio.ucla.edu (E.R.S.)

4 Department of Botany and Plant Sciences, University of California, Riverside, CA 91521, USA; E-Mail: demason@ucr.edu

5 Molecular Biology Institute, University of California, Los Angeles, CA 90095-1570, USA

$\dagger$ These authors contributed equally to this work.

* Author to whom correspondence should be addressed; E-Mail: ahirsch@ucla.edu; Tel.: +1-310-206-8673; Fax: +1-310-206-5413.

Received: 21 June 2013; in revised form: 29 August 2013 / Accepted: 13 September 2013 / Published: 26 September 2013

Abstract: Two strains, 30N-5 and 30VD-1, identified as Bacillus simplex and B. subtilis, were isolated from the rhizospheres of two different plants, a Podocarpus and a palm, respectively, growing in the University of California, Los Angeles (UCLA) Mildred E. Mathias Botanical Garden. B. subtilis is a well-known plant-growth promoting bacterial species, but $B$. simplex is not. B. simplex $30 \mathrm{~N}-5$ was initially isolated on a nitrogen-free medium, but no evidence for nitrogen fixation was found. Nevertheless, pea 
plants inoculated with $B$. simplex showed a change in root architecture due to the emergence of more lateral roots. When Pisum sativum carrying a DR5::GUSA construct, an indicator for auxin response, was inoculated with either B. simplex $30 \mathrm{~N}-5$ or its symbiont Rhizobium leguminosarum bv. viciae 128C53, GUS expression in the roots was increased over the uninoculated controls. Moreover, when pea roots were coinoculated with either B. simplex $30 \mathrm{~N}-5$ or $B$. subtilis $30 \mathrm{VD}-1$ and $R$. leguminosarum bv. viciae $128 \mathrm{C} 53$, the nodules were larger, clustered, and developed more highly branched vascular bundles. Besides producing siderophores and solubilizing phosphate, the two Bacillus spp., especially strain 30VD-1, exhibited anti-fungal activity towards Fusarium. Our data show that combining nodulating, nitrogen-fixing rhizobia with growth-promoting bacteria enhances plant development and strongly supports a coinoculation strategy to improve nitrogen fixation, increase biomass, and establish greater resistance to fungal disease.

Keywords: anti-fungal activity; lateral roots; nodulation; plant growth-promoting bacteria; phosphate solubilization; siderophores

\section{Introduction}

Soil bacteria that associate with plant roots and have a positive effect on growth are often called plant-growth promoting rhizobacteria (PGPR). The more general term plant-growth promoting bacteria (PGPB) [1], used in this report, has been utilized to describe microbes that colonize and positively impact the phytosphere, i.e., the surfaces of stems, leaves, seeds, and roots.

PGPBs fix nitrogen, secrete plant hormones or antibiotics, solubilize phosphate, inhibit pathogenic microbes, or modify insoluble $\mathrm{Fe}^{3+}$ to utilizable forms of iron $[2,3]$. In addition, soil bacteria stimulate phytoremediation and by attaching to roots, improve plant health by increasing the numbers of biodegradative bacteria [4]. Many PGPB studies focus on Gram-negative bacteria such as the pseudomonads, which are simple to culture and suitable for genetic manipulation. However, a large number of Bacillus species, Gram-positive, rod-shaped bacteria, also exhibit plant growth-promoting (PGP) activity. Their ability to produce dormant, heat- and desiccation-tolerant spores unlike Gram-negative microbes not only enables them to survive severe stress in the field, but has also led to their utilization in commerce because of the easy dispersal and long shelf life of their spores [5]. Bacillus species reported as having PGP ability include B. subtilis [6-8], B. amyloliquefaciens [9], B. pumilus [10], B. licheniformis [11], B. thuringiensis [12], B. cereus [13], B. megaterium [14], and many others. Combinations of Bacillus spp. also enhance plant growth. Researchers describe the interactions of Bacillus species as well as other Gram-positive bacteria with plants [15], whereas others present overviews of the commercial products available for plant growth promotion, several of which include Bacillus spp. [16,17].

Bacillus spp. enhance plant growth in myriad ways: By sequestering or mobilizing heavy metals in contaminated or serpentine soils [18], by controlling pathogens via induced systemic resistance (ISR) [17], by synthesizing antibiotics or volatile compounds [19-21], by producing plant hormones such as indole-3-acetic acid (IAA), cytokinin, and gibberellic acid (GA) or by reducing ethylene 
concentration via acdS (1-aminocyclopropane-1-carboxylic acid deaminase) activity [22], and/or by acting synergistically with nitrogen-fixing or phosphorous-acquiring symbiotic microbes [11,23-25]. PGP bacilli are commonly detected in the rhizosphere, phyllosphere, or as endophytes [10,26,27].

In a survey of soil bacteria isolated from the Mildred E. Mathias Botanical Garden (MEMBG), we discovered two Bacillus strains, one identified as B. simplex and the other as B. subtilis. Other than the studies reporting that certain B. simplex strains promote growth of kiwifruit [28], Arabidopsis [19], and tomato and wheat [29], few accounts describe this species as a PGPB [30-32]. On the other hand, B. subtilis strains are well known PGPBs.

Previous studies demonstrated that coinoculating legumes with rhizobia and various Bacillus species, including B. subtilis, resulted in altered root architecture and enhanced nodulation for bean [33,34], peanut [35], pigeon pea [36], and soybean [12,37]. In preliminary experiments, we found that two legume species used as models for determinate and indeterminate nodule formation, Lotus japonicus and Medicago truncatula, respectively, showed enhanced lateral root formation in response to $B$. simplex inoculation. Determinate and indeterminate nodules differ in the site of original cell divisions giving rise to the nodule, the length of the root hair that is infected, the presence of an ephemeral versus a persistent apical meristem, and the downstream stages of nitrogen assimilation [38].

In this report, we analyzed a DR5::GUS-containing Pisum sativum L. [39], an indeterminate nodule-forming legume, with the following goals: (1) To determine whether Bacillus inoculation alone would enhance the growth of pea; (2) To learn whether pea nodulation was changed upon coinoculation with Rhizobium leguminosarum bv. viciae 128C53 (Rlv) and Bacillus; and (3) To deduce likely mechanisms that could account for growth enhancement in response to Bacillus inoculation either alone or in combination with rhizobia. Pea was selected as a host plant because: (1) DR $5: \because G U S$ expression has not yet been employed to monitor the effect of bacterial inoculation on auxin response in this legume; and (2) it is a large legume making it easier to detect potentially subtle differences in dry weight and shoot length measurements. We focused on the effects of $B$. simplex inoculation because this species has been understudied compared to B. subtilis. However, because $B$. subtilis species are commonly used for biocontrol and have other PGP effects, we included B. subtilis 30VD-1, which was isolated at the same time as the B. simplex strain, in our studies.

Based on our analysis, we propose that bacteria-derived or plant-produced auxin may be one of the major factors influencing pea root architecture and growth. Furthermore, bacterial traits such as phosphate solubilization, siderophore production, and anti-fungal activity are also likely to be involved in pea growth promotion, and thus contribute to the success of a multi-species strategy for inoculating crops in the field.

\section{Results and Discussion}

The 16S rRNA gene of strains 30N-5 and 30VD-1 (Table 1) was PCR-amplified using a colony PCR procedure (see Experimental Section). A preliminary phylogenetic analysis of the nucleotide sequence for a partial $16 \mathrm{~S}$ rDNA gene showed that strain $30 \mathrm{~N}-5$ is nested within a well-supported clade ( $100 \%$ bootstrap) that includes five other B. simplex strains. We found that strain $30 \mathrm{~N}-5$ is $100 \%$ identical to Bacillus simplex $\mathrm{NH} 25$ and $>99.4 \%$ identical to all other B. simplex strains. Two 16S PCR 
products of 1465 and 1458 bp were sequenced and found to be $100 \%$ identical to B. subtilis subsp. subtilis strain 168.

To obtain even finer resolution, a phylogenetic tree was constructed with a concatenated set of four protein-encoding genes: glyceraldehyde-3-phosphate dehydrogenase (gapA), RNA polymerase beta subunit (rpoB), excision nuclease subunit A (uvrA), and phosphoglycerate kinase (pgk) [31,40]. As shown in Figure 1, strain 30N-5 is nested within the clade that contains five B. simplex strains, which are distinct from other Bacillus species previously reported to be PGPB.

Figure 1. Multilocus sequence analysis of closely related members of the genus Bacillus and position of $B$. simplex $30 \mathrm{~N}-5$ within the $B$. simplex clade based on a concatenated set of four protein-coding genes (gapA, $r p o \mathrm{~B}, u v r \mathrm{~A}, p g k)$. The bootstraps reported are listed in the order Maximum Likelihood/Neighbor Joining. Also, the values are only reported if both methods support the clade with a $>50 \%$ bootstrap value.

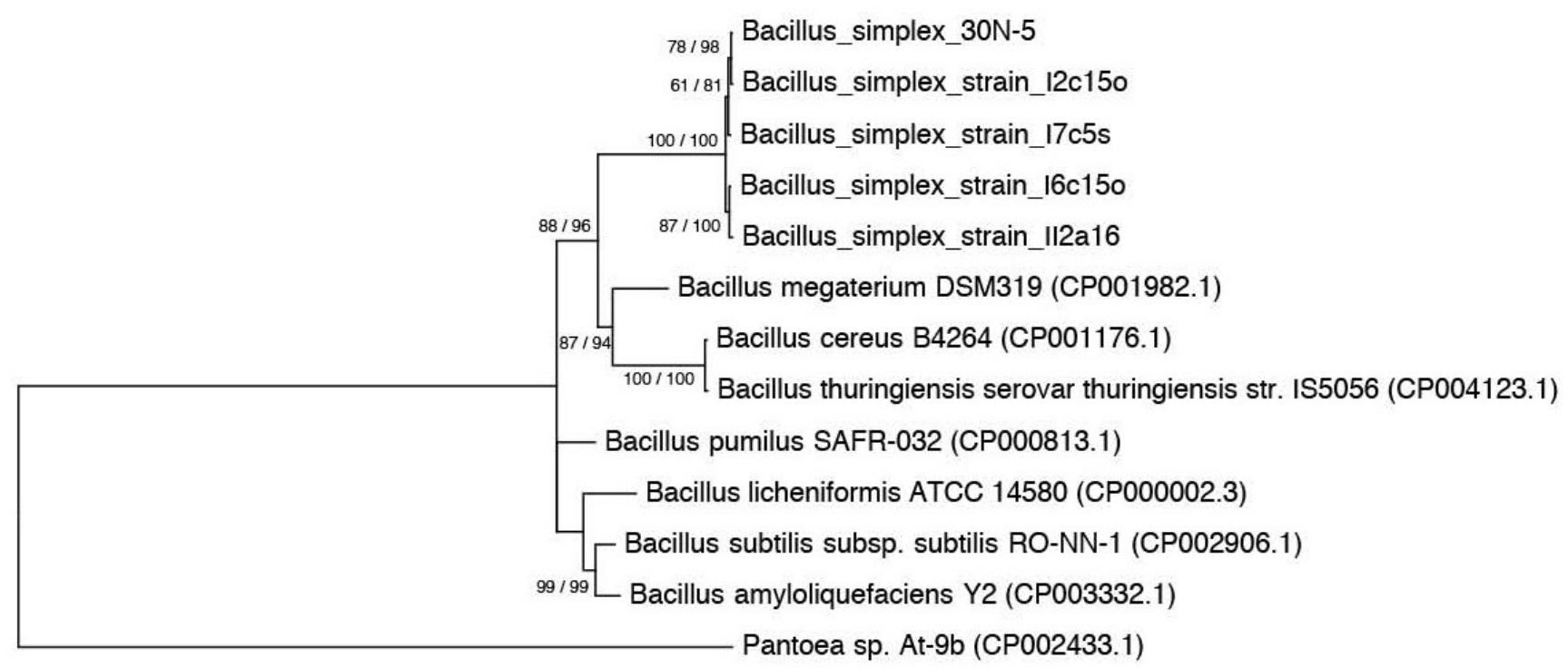

\subsection{Nitrogen Fixation Tests}

Because $B$. simplex $30 \mathrm{~N}-5$ was originally isolated on an N-free medium, primers that targeted nifH were used in a colony PCR using Sinorhizobium (Ensifer) meliloti strain 1021 as the positive control. We did not find any evidence for nifH in B. simplex 30N-5 despite the fact that we based our primer set on data from [41] and that several reports were published earlier regarding nifH presence in various Bacillus genomes [41-43]. We also found no evidence for nif genes in an analysis of a draft sequence of the B. simplex genome. Thus, we conclude, in agreement with [44] who reported that Bacillaceae lack nifH, that $B$. simplex is not a diazotroph even though $30 \mathrm{~N}-5$ was isolated on a solidified $\mathrm{N}$-free medium.

One possible explanation for its growth on medium lacking nitrogen is that B. simplex is a very good $\mathrm{N}$ scavenger. When inoculated into an N-free liquid medium, B. simplex $30 \mathrm{~N}-5$ ceased growth unless the medium was supplemented with ACC, suggesting that $B$. simplex has AcdS (1-aminocyclopropane-1-carboxylate (ACC) deaminase) activity. AcdS catalyzes the breakdown of ACC to 2-oxobutanoate and ammonia. A number of rhizosphere bacteria use ACC, the precursor of the 
plant-growth inhibitor ethylene, as a nitrogen source [45]. When B. simplex 30N-5 was cultured on an $\mathrm{N}$-free medium with or without ACC, growth occurred in liquid medium only when ACC was present. However, in solid medium, growth occurred with or without ACC. This response took place whether Bacto-Agar or Phytagar was used as a solidifying agent, suggesting that a small amount of $\mathrm{N}$ may have been present in the agar.

Table 1. Strains used in this study.

\begin{tabular}{|c|c|c|}
\hline Strain & Relevant Characteristics & Source/Reference \\
\hline Bacillus simplex $30 \mathrm{~N}-5$ & $\begin{array}{l}\text { Isolated from the rhizosphere of a } \\
\text { Podocarpus nagi tree growing in } \\
\text { the MEMBG. }\end{array}$ & This work \\
\hline Bacillus subtilis 30VD-1 & $\begin{array}{l}\text { Isolated from soil in the palm section of the } \\
\text { MEMBG, adjacent to Brahea edulis } \\
\text { (Aracaceae; Guadalupe Palm), a tree } \\
\text { indigenous to Guadalupe Island in Mexico. }\end{array}$ & This work \\
\hline Bacillus subtilis BAL218 & JH642 trpC2, pheA1 & $\begin{array}{c}\text { Beth A. Lazazzera } \\
\text { (University of California, } \\
\text { Los Angeles) }\end{array}$ \\
\hline Sinorhizobium (Ensifer) meliloti 1021 & $\begin{array}{l}\text { Wild-type } \\
\text { Sinorhizobium (Ensifer) meliloti, } \operatorname{Str}^{\mathrm{r}}\end{array}$ & Laboratory strain \\
\hline $\begin{array}{l}\text { Rhizobium leguminosarum bv. viciae } \\
\text { 128C53 }\end{array}$ & Wild-type Rlv & Laboratory strain \\
\hline $\begin{array}{l}\text { Rhizobium leguminosarum bv. viciae } \\
\text { 128C53/pHC60 }\end{array}$ & Wild-type Rlv with GFP, Tet ${ }^{\mathrm{r}}$ & This work \\
\hline $\begin{array}{l}\text { Fusarium oxysporum forma specialis } \\
\text { conglutinans race } 2 \text { PHW } 808\end{array}$ & Isolated from cabbage. & {$[46]$} \\
\hline $\begin{array}{l}\text { Fusarium oxysporum forma specialis } \\
\text { matthioli race } 2 \text { PHW } 726\end{array}$ & Isolated from Mathiola incana. & {$[46]$} \\
\hline Fusarium verticillioides NRRL 13993 & Isolated from maize ear. & {$[47]$} \\
\hline Nectria hematococca 77-113-4 & $\begin{array}{l}\text { Pea pathogen, member of the } \\
\text { Fusarium solani complex }\end{array}$ & $\begin{array}{c}\text { Martha C. Hawes } \\
\text { (University of Arizona) }\end{array}$ \\
\hline
\end{tabular}

We next utilized primers for $a c d S$ [48] to determine whether an ACC deaminase gene was present in the $B$. simplex genome. A band of the expected size was amplified and cloned into a $\mathrm{TOPO}^{\circledR}$ vector. Instead of an acdS sequence, the primers amplified products that were determined to encode histidyl-tRNA synthetase, acetyl CoA acetyltransferase, and D-fructose-6-phosphate amidotransferase based on NCBI BLAST. Previously, an endophyte identified as B. simplex XAS5-3 was shown to exhibit low levels of ACC deaminase activity [22]. We next checked the draft genome of $B$. simplex $30 \mathrm{~N}-5$ and found it contains a sequence with high identity to a gene encoding a pyridoxal phosphate-dependent enzyme. ACC deaminase is a member of this family of enzymes, and in Bacillus spp., these genes are often annotated as acdS. Nonetheless, experimental evidence will be needed to prove whether or not this gene actually encodes AcdS, but in any case, its putative presence 
in the $B$. simplex draft genome suggests the reason for the initial selection of strain $30 \mathrm{~N}-5$ on an $\mathrm{N}$-free medium.

\subsection{Inoculation with B. simplex 30N-5 Alters Root Architecture}

Because several B. simplex strains are reported to be PGPBs, we choose to study strain $30 \mathrm{~N}-5$ 's plant growth-promoting capabilities, specifically as a helper for nodulation. We found that lateral root number increased in response to B. simplex inoculation compared to the control (uninoculated) when peas were grown in $+\mathrm{N}$ medium as early as 14 days following inoculation (dpi) (Figure 2) and that the difference from the control was statistically significant (Figure 3a). When pea plants grown in $-\mathrm{N}$ medium were either left uninoculated, inoculated with B. simplex or B. subtilis or Rlv singly, or mixed with either Bacillus species and Rlv in a 1:1 ratio, only a slight change in root architecture was observed for B. simplex-inoculated plants 14 and 18 dpi (Figure 3a). For Rlv-inoculated plants, the number of lateral roots decreased by $18 \mathrm{dpi}$. With respect to shoot length, no obvious statistical difference was observed 18 dpi (Figure 3b) although in some cases, greater root development led to taller plants (Figure 2).

Figure 2. Change in pea root architecture for either (a) uninoculated plants or (b) plants inoculated with B. simplex $30 \mathrm{~N}-5$ and grown in a $+\mathrm{N}$ medium for 2 weeks, Bar, $1 \mathrm{~cm}$.

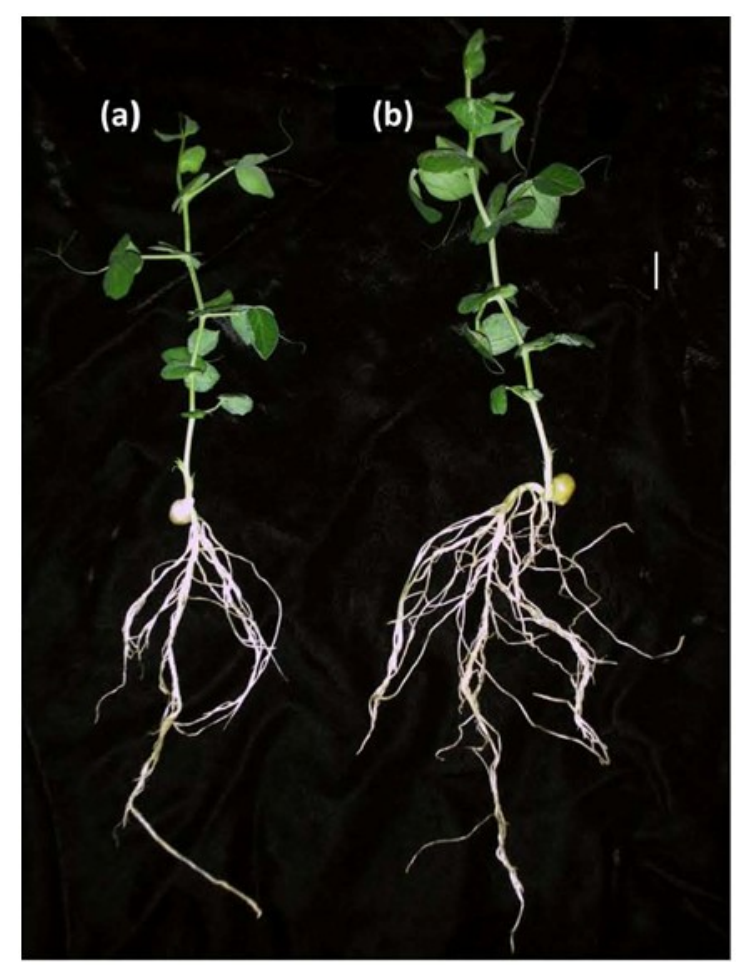

Plants were grown in pots for the dry weight measurements because root volume was likely to be less constrained than in Magenta jars. The largest increase in root dry weight occurred following B. simplex inoculation. By contrast, B. subtilis and Rlv-inoculated root dry weight increases did not statistically differ from that of the uninoculated control (Figure 3c) although a trend towards increased biomass was suggested. No difference was observed among the treatments with respect to shoot dry weight. 
Figure 3. Growth measurements of uninoculated and inoculated pea plants grown in Magenta jars (a,b) or pots (c); (a) Average number of lateral roots 14 dpi and 18 dpi from either four or six different treatments including the uninoculated control (without or with $\mathrm{N}$ ); B. simplex (without or with $\mathrm{N}$ ) or Rlv alone (without $\mathrm{N}$ ) and the two bacteria mixed together in a 1:1 ratio (without $\mathrm{N}$ ); (b) Same treatment as above, but shoot length measurements were made $18 \mathrm{dpi}$; (c) Effect of Bacillus strains on pea root biomass. Peas inoculated with B. simplex, B. subtilis, or R. leguminosarum bv. viciae, or left uninoculated were grown in pots in a UCLA Plant Growth Center greenhouse $\left(22.3{ }^{\circ} \mathrm{C}\right)$ under $\mathrm{N}$-deficient conditions $(-\mathrm{N})$. At $18 \mathrm{dpi}$, roots were isolated and dried at $55{ }^{\circ} \mathrm{C}$ for $48 \mathrm{~h}$. For $\mathbf{a}-\mathbf{c}$, the number of plants measured per treatment was 8-10. All experiments were repeated at least 3 times. Significance between means was tested, after a variance analysis was performed, using Duncan's Multiple Range test at $p<0.05$. Standard errors are illustrated.

\section{(a)}

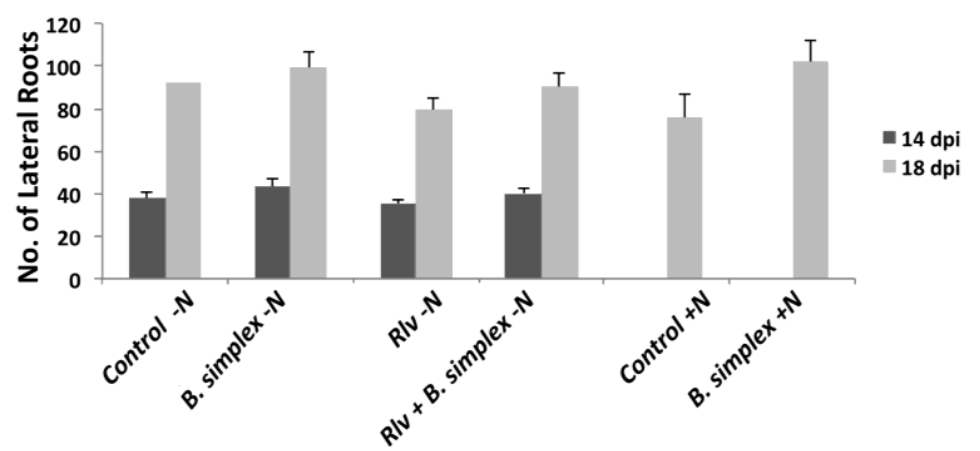

(b)

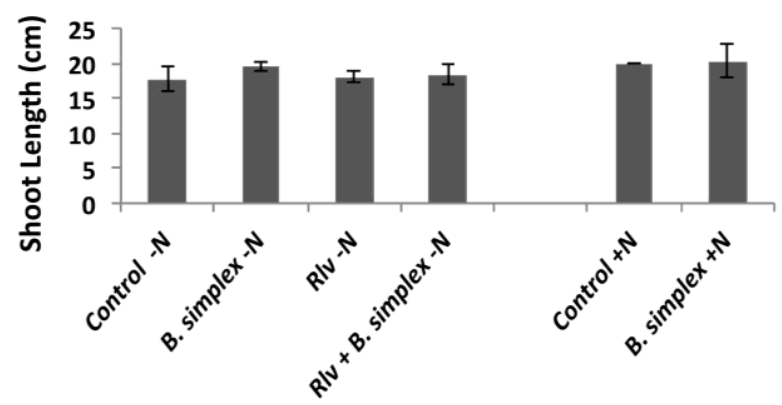

\section{(c)}

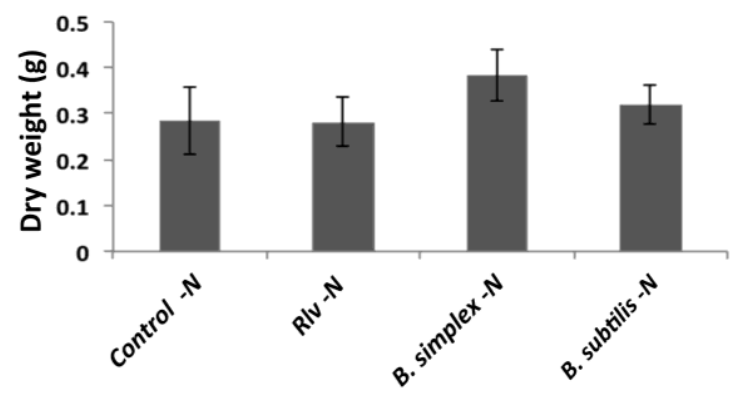

Treatment 
Many B. subtilis strains synthesize auxin [49], but because so few B. simplex strains have been studied, it is not known whether they share this ability. IAA secreted into the growth medium of B. simplex cultures incubated with varying concentrations of L-tryptophan (an IAA precursor) was measured following published procedures (see Experimental Section). A positive linear relationship between the concentration of L-tryptophan and the Optical Density ratio $\left(\mathrm{OD}_{535 / 600}\right)$ was seen indicating the presence of auxin in the supernatant (Appendix Figure A1). No positive correlation was observed between the absorbance ratios and the varying L-tryptophan concentrations in uninoculated control experiments or in the medium alone (data not shown).

\subsection{Effects on Nodulation in Response to Rhizobium leguminosarum $b v$. viciae}

Because auxin has been implicated in both nodulation and lateral root formation and because B. simplex secretes IAA, we utilized pea plants with a DR5::GUS promoter. These stable transgenic lines were originally developed to monitor auxin activity and response in vegetative and reproductive tissues [39]. GUS expression was detected in embryos, root tips, developing flowers, procambial cells, and pollen - sites known to correlate with high auxin concentrations.

Upon inoculation with either $B$. simplex $30 \mathrm{~N}-5$ or Rlv singly or mixed together in a 1:1 ratio, an increase in GUS expression in pea root tips over the uninoculated controls was observed (Figure 4a-c). Because nodules developed only after Rlv inoculation, the blue color first became apparent within inner cortical cells in close association to the root vascular bundle (vb) where nodules originate (Figure 4d). Nodules of varying developmental stages that stained positively for GUS activity are illustrated in Figure 4e,f. Immature but emergent nodules exhibited terminal GUS staining (Figure 4e). With maturity, the staining of the nodule meristem lessened, but the GUS stain remained closely associated with the immature vascular bundles of the developing nodule (Figure $4 \mathrm{f}$ ).

\subsection{Nodulation in Response to Coinoculation}

The most striking phenotype resulting from the mixed inoculation experiments was the increase in nodule size as well as the clustering of nodules (Figures $4 \mathrm{c}$ and 5). A similar response occurred with B. subtilis 30VD-1 coinoculated with Rlv for pea plants that were grown in pots in the greenhouse. Like the B. simplex-Rlv coinoculation, the nodules were clustered and redder than the nodules initiated by Rlv alone.

As described above for Rlv only, the earliest stages of nodule development took place in the inner cortex and the young, emergent nodules exhibited GUS staining in the nodule meristem and in the vascular bundles (Figure 5b). In some young nodules, the nodule meristem lost the blue color early in development (Figure 5c) whereas in others, the color was evident even in the later stages (Figure 5d). More mature nodules exhibited additional branching of the vascular bundles with the distal areas losing GUS staining as the vascular bundles matured (Figure 5e,f).

Figure 5g illustrates a near-median, sagittal [50] section of a nodule stained for GUS (arrow). The interior cells of the nodule are occupied by bacteroids. Examination at a higher magnification did not reveal any confirmable bacilli or spores in or between nodule cells. Attempts to determine whether bacilli were present using an antibody against Bacillus spore walls or a specific staining reaction to identify Gram-positive organisms in sectioned material [51] were unsuccessful. 
Figure 4. GUS staining of pea roots and nodules 14 dpi; (a) Uninoculated control. GUS staining is mostly localized to the lateral root primordia and the youngest root tips; (b) Root inoculated with $R$. leguminosarum bv. viciae. The blue color is detected in the nodules (arrows), lateral root primordia, and in young root tips; (c) Root coinoculated with B. simplex and Rlv. The nodules (white arrowheads) are larger and clustered closer to the crown of the root. Bar, $1 \mathrm{~cm}$; (d) Nodule primordium (black arrow) 10 dpi with $R$. leguminosarum bv. viciae. The white arrow points to a vascular bundle (vb); (e) Emergent nodule (ca. 14 dpi) with GUS staining in the nodule meristem (m) and young vascular bundles; (f) Staining is apparent in the nodule meristem (m) and most recently developed vascular bundles (vb) (arrow); 32 dpi; Bars, $200 \mu \mathrm{m}$.

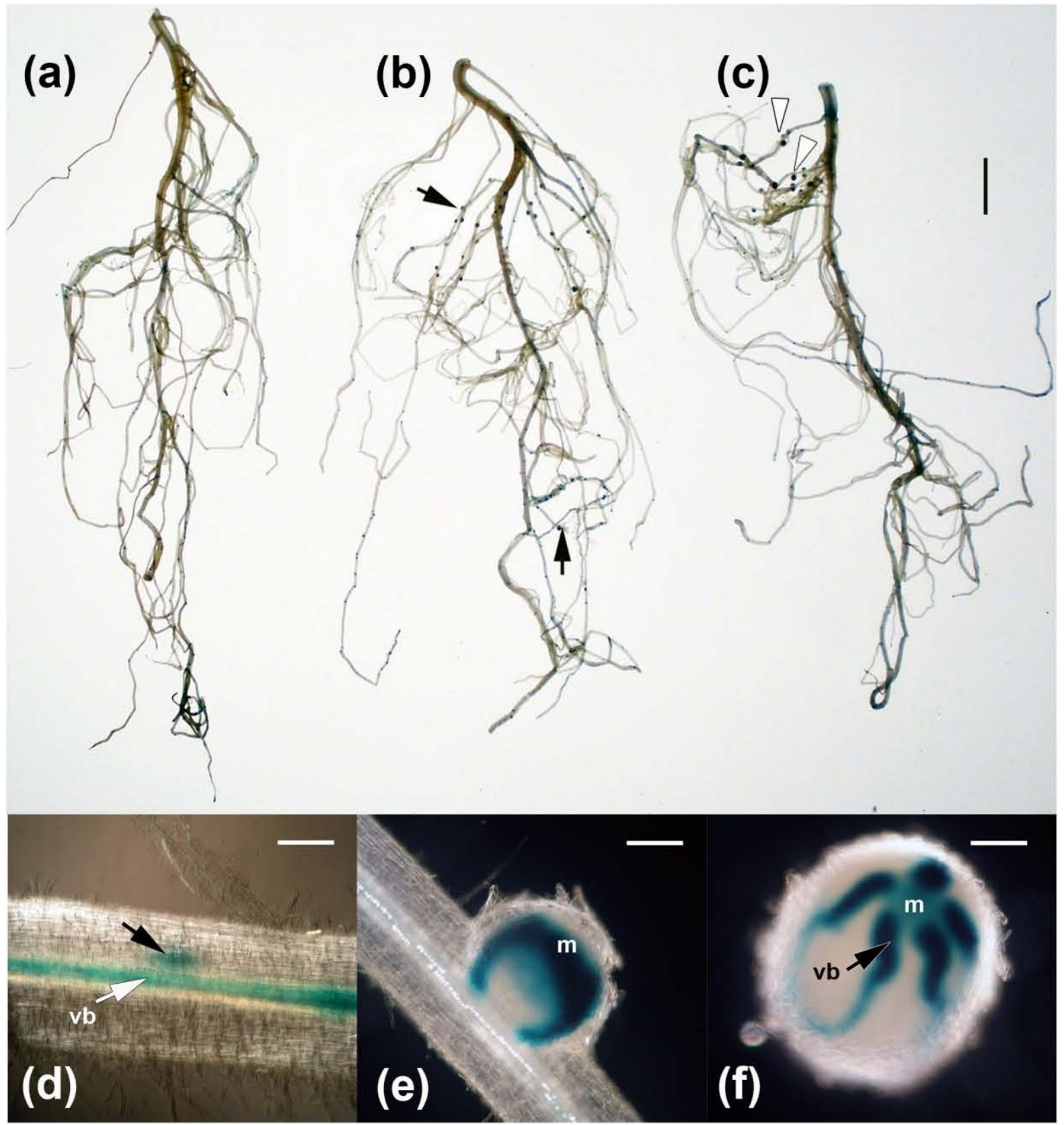


Figure 5. Effect of coinoculation; (a) A cluster of nodules of different ages showing GUS staining in the young vascular bundles; $32 \mathrm{dpi}$. The red color is due to the presence of leghemoglobin. Bar, $2 \mathrm{~mm}$; (b) A young nodule (14 dpi) exhibits localization of GUS activity in the nodule meristem (m) and young vascular bundles (vb); (c) Loss of GUS staining in the nodule meristem (m); $14 \mathrm{dpi}$; (d) Retention of some GUS staining in the meristem (m); $32 \mathrm{dpi}$; (e) Branching of the vascular bundles in a more mature nodule; 32 dpi; (f) A nodule with extensive vascular development; 32 dpi; (g) Near-median plastic section of a 26 dpi nodule originally stained for GUS, which is localized towards the apical end near the vascular bundle (arrow). The section was stained with safranin $O$. Bars for (b) through (g), $200 \mu \mathrm{m}$.

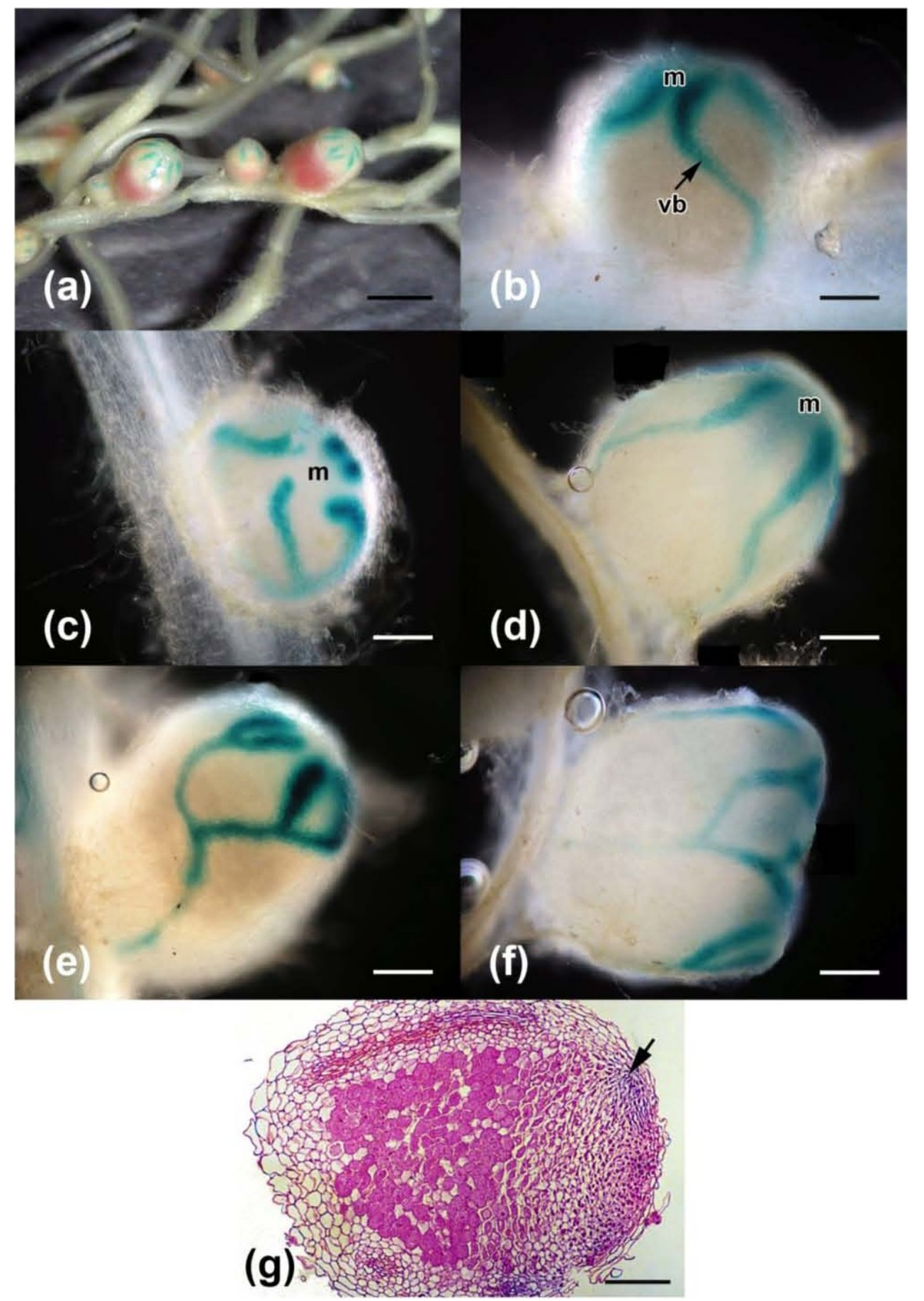


To determine whether both bacterial species were found in the nodules from coinoculated plants, we squashed surface-sterilized nodules to look for Rlv/pHC60 versus bacteria of a different morphology or lacking GFP. Table 2 shows the numbers of bacteria recovered from suspensions obtained from one Rlv/pHC60-nodule and three nodules of a coinoculated plant. Three colonies, one from a nodule removed from an Rlv/pHC60-inoculated plant and two from nodules of coinoculated plants, were chosen for PCR analysis to verify that both strains were present in the nodule. The GFP-fluorescing colony derived from the Rlv/pHC60 nodule was identified as Rlv (99\% identity over $329 \mathrm{bp}$ ). The non-fluorescent colonies isolated from nodules of coinoculated plants were identified as Bacillus sp. (97\%, 329 bp) and B. simplex (99\%, 890 bp). Thus, both bacterial species are housed within nodules although $B$. simplex is significantly outnumbered.

Table 2. Recovery of bacteria from nodules of Rhizobium leguminosarum bv. viciae-inoculated and coinoculated plants.

\begin{tabular}{ccccccccc}
\hline Dilution & \multicolumn{2}{c}{$\begin{array}{c}\text { Rlv/pHC60- } \\
\text { inoculated }\end{array}$} & \multicolumn{2}{c}{ Coinoculated 1 } & \multicolumn{2}{c}{ Coinoculated 2 } & \multicolumn{2}{c}{ Coinoculated 3 } \\
\hline & Total \# & Non-GFP & Total \# & Non-GFP & Total \# & Non-GFP & Total \# & Non-GFP \\
colonies & colonies & colonies & colonies & colonies & colonies & colonies & colonies \\
$1: 100$ & 247 & 0 & n.d. * & n.d. & 435 & 1 & n.d. & n.d. \\
$1: 1000$ & n.d. & n.d. & 88 & 3 & 126 & 2 & 136 & 1 \\
\hline \multicolumn{3}{c}{ * The 1:10 dilutions and the columns indicated by "not determined" (n.d.) contained either no or too many } \\
\multicolumn{3}{l}{ bacteria to count. }
\end{tabular}

Nodule clustering following coinoculation with Rlv and either Bacillus strain might be a consequence of increased root hair development as reported by [34] for bean, or alternatively, caused by the branching of the nodule primordium. It is well known that lateral root development is positively influenced by auxin treatment and this might also affect nodule status. The clustering of nodules and their increased size is likely to be correlated with the increase in the number of vascular bundles, brought about by branching of the nodule primordia under coinoculation conditions. Auxin, when applied exogenously, increases root mass both by stimulating the elongation of the primary root, and by increasing the number of lateral roots [14]. Increased root mass due to more lateral roots enhances the plants' ability to anchor themselves in the soil, enables them to obtain increased amounts of water and mineral nutrients through increased root surface area, and promotes the extension of the primary roots into deeper soil levels sooner after seed germination [52].

In earlier studies, M. truncatula plants inoculated with S. meliloti 1021, either engineered to overproduce IAA (strain RD64) by introducing a plasmid encoding the indole-3-acetamide pathway or supplemented with $0.5 \mathrm{mM}$ IAA, exhibited increased nitrogen fixation, which was linked to the improved phosphate solubilization activity of $S$. meliloti strain RD64 and IAA-supplemented strain 1021 [53]. Also, the RD64 and IAA-treated 1021 strains induced the formation of M. truncatula nodules that had a significantly larger nodule meristem, resulting in increased nodule size, nitrogen fixation, and stem dry weight [54]. These descriptions resemble the phenotypes observed for peas coinoculated with Rlv and B. simplex, although [54] did not report whether the nodule vasculature was more elaborated or whether the nodules were clustered together. 


\subsection{Mechanisms by Which B. Simplex 30N-5 and B. Subtilis 30VD-1 Could Promote Plant Growth}

Because "direct mechanisms of plant growth promotion are difficult to differentiate from disease suppression" [16], we first investigated whether the B. simplex strain promoted plant growth by producing siderophores or solubilizing phosphate, two basic mechanisms of plant growth promotion. Moreover, the ability of the Bacillus strains to solubilize phosphate and produce siderophores might also be involved in enhancing nodule function. Bacterial siderophore production promotes growth by supplying iron directly to the plant or by depriving other microbes, potentially deleterious ones, of iron [55]. We found that strains 30N-5 and 30VD-1 were able to solubilize phosphate and synthesize siderophores (Appendix Figure A2). On the other hand, other known B. simplex strains, such as $B$. simplex KBSIF-3 [29] and B. simplex XAS35-3 [22] do not exhibit these activities. Evidence for siderophore function was found in the $B$. simplex $30 \mathrm{~N}-5$ draft genome.

Next, anti-fungal activity was investigated for B. simplex $30 \mathrm{~N}-5$ and two different $B$. subtilis strains: BAL218 and 30VD-1 (Table 1). BAL218 was used to compare the activity of a typical laboratory strain with that of a newly isolated B. subtilis. The Bacillus strains and various Fusarium species [46,47] were co-cultured first on Potato Dextrose Agar (PDA) because this medium is routinely used. However, B. subtilis BAL218 growth was poor on PDA, so we tried Czapek Dox agar and Malt Extract agar (MEA), but neither B. simplex nor B. subtilis BAL218 grew robustly on these two media. Also, PDA did not support $B$. simplex growth as well as that of B. subtilis 30VD-1, making it difficult to evaluate the antagonistic activity of strain $30 \mathrm{~N}-5$ towards Fusarium species. For example, in tests against F. oxysporum f. sp. conglutinans PHW 808 (FOC) and $F$. verticillioides FV3 X0042 (Fv), B. subtilis 30VD-1 significantly inhibited Fv radial growth compared to the uninoculated control whereas $B$. simplex $30 \mathrm{~N}-5$ did not (Figure 6a). By contrast, $B$. simplex reduced $\mathrm{Fv}$ growth, but again it was not as effective at doing so as was $B$. subtilis 30VD-1 (Figure 6b). This result led us to use V8 agar and solidified ISP2, both of which support bacterial and fungal growth better than PDA [56,57].

B. simplex $30 \mathrm{~N}-5$ grew well on V8 medium, either filtered or unfiltered, and exhibited its most active anti-fungal activity on this substrate. However, the laboratory strain BAL218 was ineffective on all media tested, and so it was dropped from further tests. In subsequent experiments, two other fungi were included along with FOC, namely F. oxysporum f. sp. matthioli PHW 726 (FOM) and the pea pathogen Nectria haematococca 77-13-4 (Nh) (Table 1). As can be seen in Figures 6c-e, the mean radial growth of all uninoculated fungi was much improved in V8 agar compared to PDA (Figures 6a,b). In addition, each fungal species responded differently to this medium with FOM expanding more extensively than $\mathrm{Nh}$, which grew better than FOC.

On V8 agar, an inhibitory effect of $B$. simplex on FOM radial expansion was apparent 72 hours after the start of the experiment and was obvious by day 4 (Figure 6c). Nevertheless, B. subtilis 30VD-1 remained a more potent antagonistic agent, restricting fungal growth by more than $31 \%$ compared to $9 \%$ inhibition for $B$. simplex after 3 days (Figure $6 \mathrm{~d}$ ). By day $6, B$. simplex had reduced FOM radial expansion by ca. $28 \%$ whereas $B$. subtilis $30 \mathrm{VD}-1$ inhibited growth by $53 \%$ (cf. Figure $6 \mathrm{c}, \mathrm{d}$ ). FOC growth was inhibited by $B$. simplex on V8 agar 4 dpi (Figure 6e) in contrast to PDA, where B. simplex grew poorly (Figure 6a), and ISP2 media. Conversely, B. subtilis 30VD-1 was a robust fungal antagonist, reducing fungal growth by $50 \%$ or more after 6 days of co-cultivation. In general, $B$. 
simplex $30 \mathrm{~N}-5$ was not as effective an antagonistic agent as strain $30 \mathrm{VD}-1$ in part because of its reduced growth on many of the co-cultivation media. B. simplex $30 \mathrm{~N}-5$ limited fungal radial expansion to about one-half the level of that of B. subtilis 30VD-1, and on V8 agar, Nh fungal hyphae became transparent (Figure 7), most likely due to altered hyphal growth on the side adjacent to the bacteria. SEM studies observed that Colletotrichum acutatum hyphae appeared lysed and spores degraded in response to B. subtilis inoculation [20]. Whether Nh transparency in response to B. simplex $30 \mathrm{~N}-5$ resulted from cell lysis or an inhibition of aerial hyphae needs further study.

Figure 6. Effect of B. simplex 30N-5 (red line) and B. subtilis 30VD-1 (green line) on the growth of fungi on either PDA (a,b) or V8 agar (c-e). The fungal species tested were: (a) Fusarium oxysporum f. sp. conglutinans PHW 808 (FOC); (b) Fusarium verticillioides FV3 X0042 (Fv); (c) Fusarium oxysporum f. sp. matthioli PHW 726 (FOM); (d) Nectria haematococca 77-13-4 (Nh); and (e) Fusarium oxysporum f. sp. conglutinans PHW 808 (FOC). The blue line illustrates the radial growth of the fungus in the absence of bacteria over a 6 or 7-day period. Standard errors are illustrated.

(a)

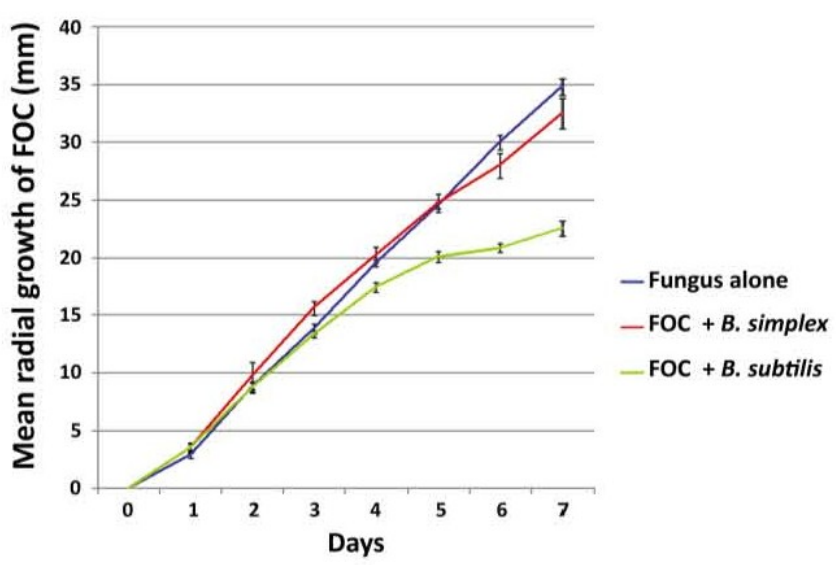

(b)

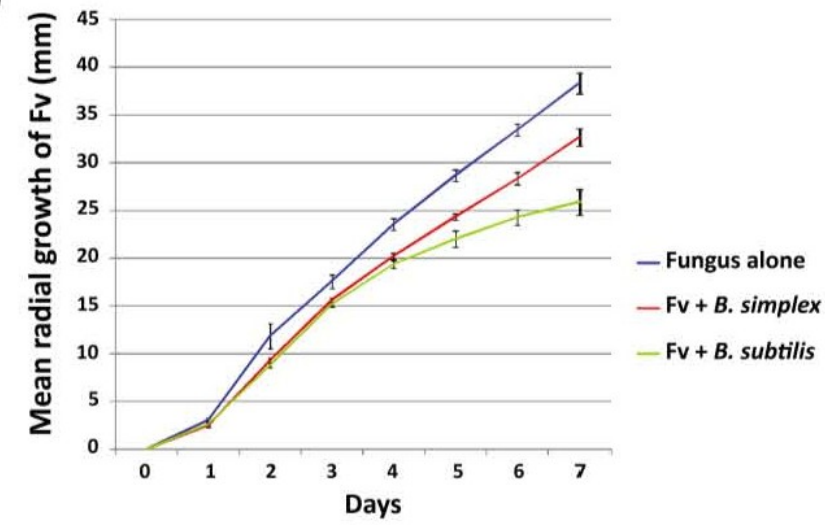

(c)

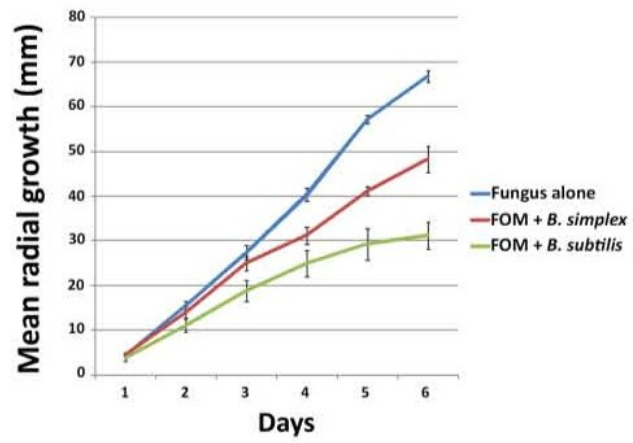

(d)

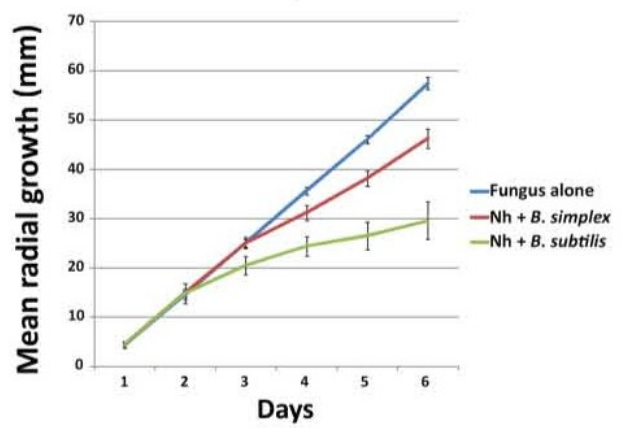

(e)

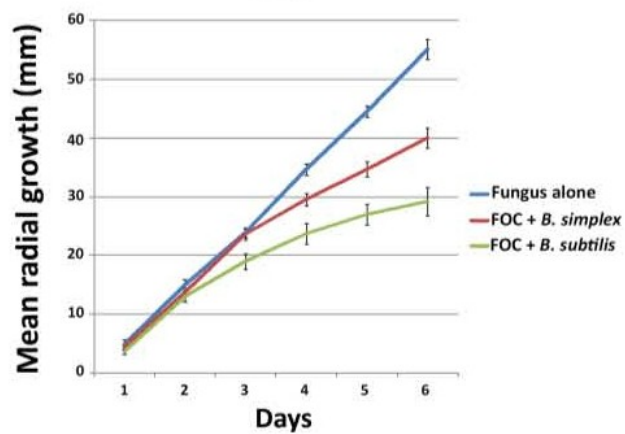


Figure 7. Effect of Bacillus strains on fungal growth. Responses of FOC (a) and FOM (b) to water (negative control), B. subtilis 30VD-1, and B. simplex 30N-5 following 13 days of culture on filtered V8 agar. B. subtilis 30VD-1 has almost completely surrounded the fungal culture. $B$. simplex limits the growth of both FOC and FOM, but not as much as the 30VD-1 strain does (middle column); (c) Response of Nectria haematococca 77-13-4 to the negative control and to the Bacillus strains on filtered V8 agar. An increase in transparency of the fungus is observed on the side closest to the B. simplex $30 \mathrm{~N}-5$ streak (arrow), whereas for the uninoculated control, the appearance of the fungal colony is the same throughout. B. subtilis 30VD-1 has almost completely surrounded the fungus.

(a)

Fusarium oxysporum f. conglutinans 808 (FOC)

\section{(b)}

Fusarium oxysporum f. sp. matthioli PHW 726 (FOM)

\section{(c)}

\section{Nectria hematococca 77-13-4}

(Nh)
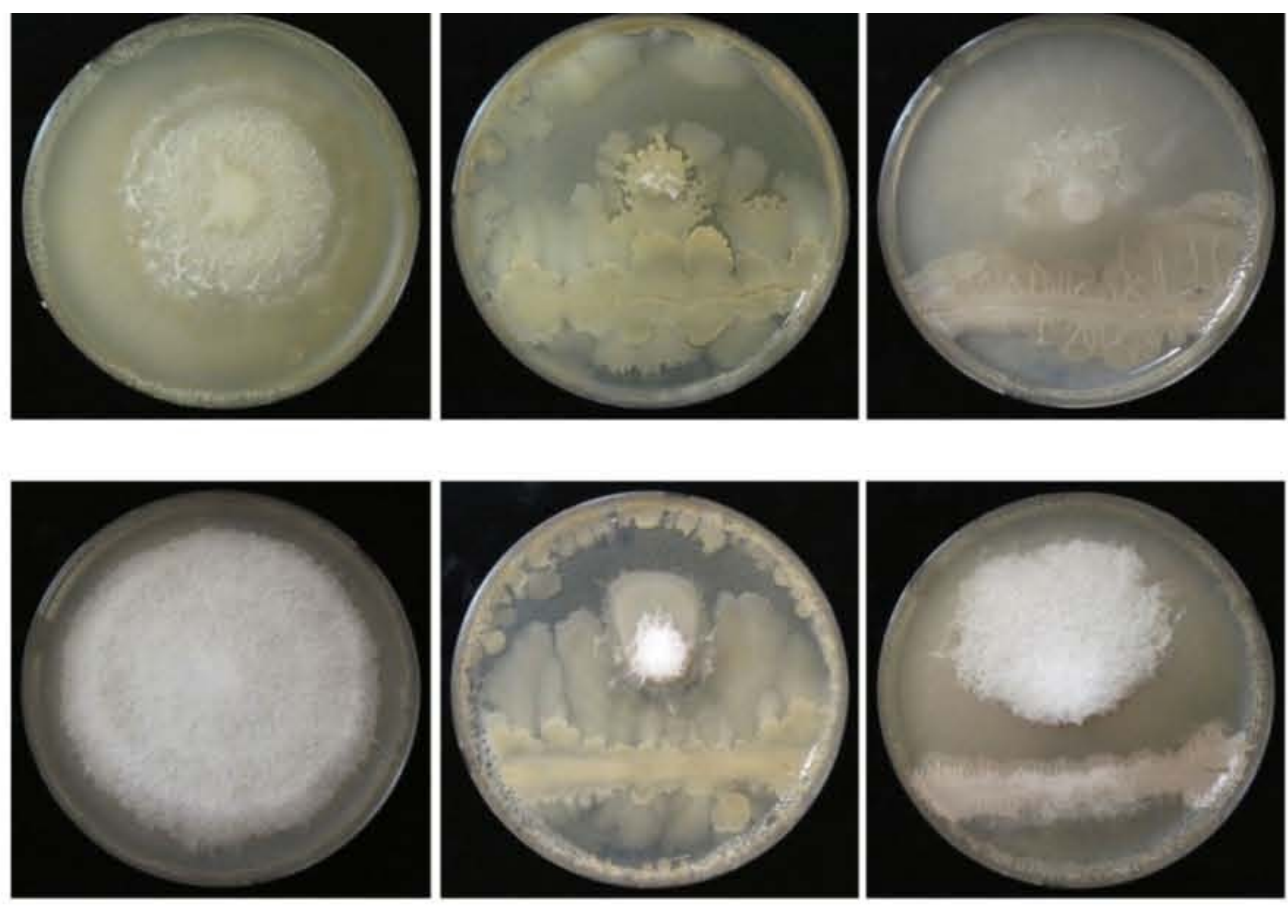

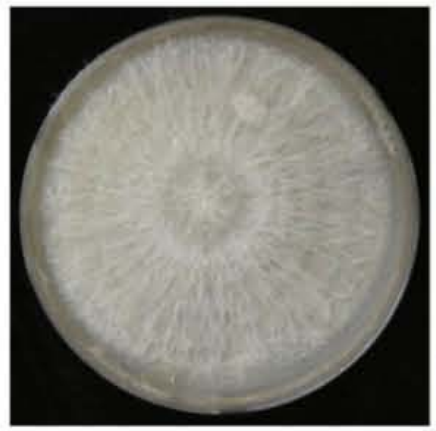

Water control

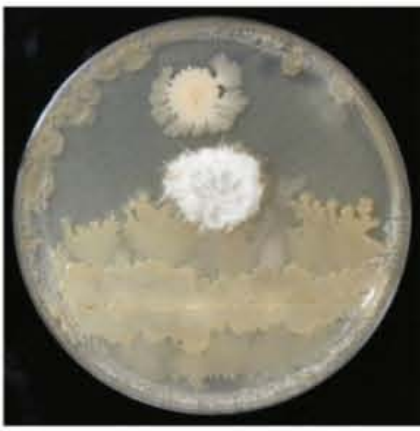

Bacillus subtilis 30VD-1

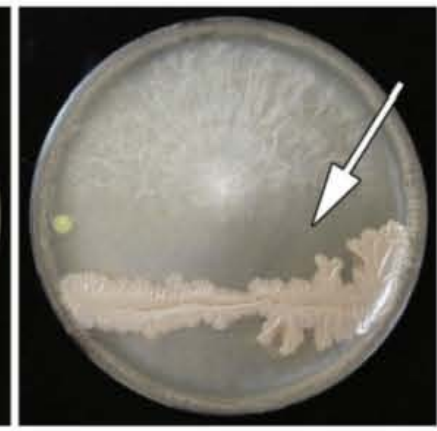

Bacillus simplex $30 \mathrm{~N}-5$

In summary, both $B$. simplex $30 \mathrm{~N}-5$ and $B$. subtilis $30 \mathrm{VD}-1$ exhibited anti-fungal activity and thus have potential for use in biocontrol. Our next step will be to determine in greenhouse experiments whether these Bacillus strains limit plant disease in response to fungal inoculation. Taken together, these data demonstrate that an approach of mixing nitrogen-fixing rhizobia and bacteria with PGP and anti-fungal activity increases legume growth and biomass production. Such a strategy should prove efficacious under field conditions, but more testing is needed. 


\section{Experimental Section}

\subsection{Routine Bacterial Growth Conditions}

Soil samples were collected from the rhizospheres of plants growing in UCLA MEMBG (Table 1). For the first isolate, serial dilutions of the soil were plated on an agar-solidified modified BAP medium without nitrogen [58] and incubated at $30{ }^{\circ} \mathrm{C}$ for several days. Repeated streak plating of individual colonies was conducted on the same medium until purified isolates, named $30 \mathrm{~N}-5$, were obtained. The second strain, strain 30VD-1, was isolated from soil in a different section of the MEMBG (Table 1) and originally propagated on VXylA medium [59] in the dark at $30{ }^{\circ} \mathrm{C}$. Unless otherwise noted, B. simplex $30 \mathrm{~N}-5$ and the B. subtilis strains were grown on LB (Luria-Bertani) [60] or TY [61] media, at either $30^{\circ} \mathrm{C}$ or $37^{\circ} \mathrm{C}$. The rhizobial strains were grown in Rhizobium Defined Medium (RDM) [62] and prepared for inoculation as described for B. simplex (Section 3.8). Antibiotics were used at the following concentrations: $50 \mu \mathrm{g} / \mathrm{mL}$ streptomycin (str), $10 \mu \mathrm{g} / \mathrm{mL}$ tetracycline (tet), and $100 \mu \mathrm{g} / \mathrm{mL}$ ampicillin (amp).

\subsection{Amplification, Purification, and Sequencing of the $16 S$ rRNA Gene}

Bacteria were suspended from a single $B$. simplex colony grown on LB plates into $20 \mu \mathrm{L}$ of sterile-filtered water. For B. subtilis 30VD-1, genomic DNA was extracted from two independent colonies and the 16S DNA was amplified as described below.

The gene for a 16S rRNA was amplified by PCR using the forward primer fD1 and the reverse primer rD1 [63] (Appendix Table A1). Amplification was performed in a total volume of $20 \mu \mathrm{L}$ containing $15 \mu \mathrm{L}$ sterile-filtered water, $2 \mu \mathrm{L}$ of bacterial sample, $2 \mu \mathrm{L}$ of $10 \times$ Taq Buffer $\left(\mathrm{MgCl}_{2}\right)$, $0.2 \mu \mathrm{L} \mathrm{fD1}$ and $\mathrm{rD} 1(3.2 \mathrm{pmole} / \mu \mathrm{L}), 0.2 \mu \mathrm{L}$ dNTPs, and $0.2 \mu \mathrm{L}$ Taq DNA polymerase. Amplified 16S rDNA products were visualized with ethidium bromide both in the gel and in the gel electrophoresis running buffer, and purified from a $0.8 \%$ low-melting point agarose gel $(100 \mathrm{~V}$, $400 \mathrm{~mA}, 1 \mathrm{~h})$. The gel extraction was performed with the Invitrogen Quick Gel Extraction Kit according to the manufacturer's directions.

To sequence the DNA fragments, the dideoxynucleotide chain-termination method was used. The sequencing reaction was performed in a total volume of $10 \mu \mathrm{L}$, containing $5.8 \mu \mathrm{L}$ purified DNA, $2 \mu \mathrm{L}$ $5 \times$ Seq buffer, $2 \mu \mathrm{L}$ BigDye ${ }^{\circledR}$, and $0.2 \mu \mathrm{L} \mathrm{fD1}$ or rD1. The conditions were: 2 min at $96{ }^{\circ} \mathrm{C}, 40$ cycles of $10 \mathrm{~s}$ at $96{ }^{\circ} \mathrm{C}, 5 \mathrm{~s}$ at $57{ }^{\circ} \mathrm{C}$, and $4 \mathrm{~min}$ at $60{ }^{\circ} \mathrm{C}$. DyeEx2.0 Spin Columns were used to clean the sequencing reactions. The reaction mixture was sequenced at the UCLA GenoSeq Core sequencing facility, and analyzed using the nucleotide BLAST program [64].

\subsection{Phylogenies}

Phylogenetic analyses were carried out using MEGA5 [65] on two different datasets. One dataset was a set of $16 \mathrm{~S}$ ribosomal RNA genes, aligned using the Muscle algorithm and trimmed to 836 positions. A second dataset consisted of a concatenated set of four protein-coding genes: glyceraldehyde-3-phosphate dehydrogenase ( gapA), RNA polymerase beta subunit (rpoB), excision nuclease subunit A $(u v r A)$, and phosphoglycerate kinase (pgk) [31,40]. Nucleotide sequences 
for each protein-coding gene set were individually aligned using the Muscle algorithm on the amino-acid translation of the nucleotide sequences. Aligned amino acid sequences were back translated into the original nucleotide sequences after alignment and manually concatenated into a single alignment of 2966 nucleotide positions. Phylogenetic reconstruction for each nucleotide alignment (16S and concatenated protein-coding) was carried out using the Maximum Likelihood algorithm with the following options: Jukes-Cantor model; gamma + invariant; 5 gamma categories; all sites used; heuristic $=$ NNI. Bootstraps (500) were calculated for each tree using Maximum Likelihood (identical parameters to tree calculation) and neighbor joining with the following parameters: Maximum composite likelihood distances, gamma parameter $=1$; pairwise deletion. Both sets of bootstrap values are shown in each tree (ML/NJ) and bootstraps are only reported if the clade has $>50 \%$ support.

\subsection{Amplification, Purification, and Sequencing of a Putative nifH Gene}

Degenerate primers designed to target nifH were based on those reported in [41] (Appendix Table A1). Amplification was described as above, but with nifH primers and $0.2 \mu \mathrm{L}$ DMSO. Amplified gene products running at the same distance as an $S$. meliloti nifH PCR product were visualized and purified from $1 \%$ low-melting point agarose gels $(100 \mathrm{~V}, 1 \mathrm{~h}, 400 \mathrm{~mA})$ and sequenced as described.

Cloning was performed using the Invitrogen TOPO ${ }^{\circledR}$ TA Cloning Kit with the pCR $^{\circledR} 2.1-$ TOPO $^{\circledR}$ vector. To confirm successful cloning, the four samples of DNA obtained from the mini-prep were cut with EcoRI to separate the putative nifH insert from the cloning vector. After confirmation of the presence of a band of the expected size for nifH, the DNA from the miniprep samples was prepared for sequencing as described above. The sequencing reactions were taken to the UCLA GenoSeq facility, and sequence outputs were analyzed using NCBI nucleotide BLAST.

\subsection{PCR Amplification of a Putative acdS Gene}

Degenerate PCR primers [48] (Appendix Table A1) and amplification as described above were used to detect the $a c d S$ gene. The putative $a c d S$ gene products were visualized and purified from a $1 \%$ lowmelting point agarose gel. The PCR product was extracted, cloned, and sequenced as described above in Section 3.4.

\subsection{ACC Utilization Assay}

For testing whether $B$. simplex $30 \mathrm{~N}-5$ could utilize ACC as a sole $\mathrm{N}$ source, the bacteria were grown on either solid or liquid Dworkin and Foster (DF-N) minimal medium without nitrogen [45]. To make DF medium N-limiting, $\left(\mathrm{NH}_{4}\right)_{2} \mathrm{SO}_{4}$ was omitted and $30 \mu \mathrm{mol}$ of ACC (Calbiochem-Novobiochem Corp., La Jolla, CA, USA) were added. The plates were incubated for $48 \mathrm{~h}$ at $30{ }^{\circ} \mathrm{C}$ because temperatures higher than $30{ }^{\circ} \mathrm{C}$ may inhibit ACC deaminase activity.

\subsection{Detecting IAA in B. simplex 30N-5 Growth Medium Supernatant}

To determine whether $B$. simplex produces the phytohormone IAA, the procedure of [52] was followed. $5 \mathrm{~mL}$ of DF salts minimal medium [45] were inoculated with $B$. simplex for overnight 
culture. $20 \mu \mathrm{L}$ of this culture were transferred into $5 \mathrm{~mL}$ DF medium supplemented with varying concentrations of L-tryptophan (from a sterile-filtered $2 \mathrm{mg} / \mathrm{mL}$ stock prepared in warm water) at 0,50 , $100,200,500,800 \mu \mathrm{g} / \mathrm{mL}$, and incubated for $42 \mathrm{~h}$ with shaking at $37^{\circ} \mathrm{C}$. The density of each culture was measured at $\mathrm{OD}_{600}$. The cells were removed from the culture medium by centrifugation $(5500 \times \mathrm{g}$ for $10 \mathrm{~min}$ ), and the supernatant retained. $1 \mathrm{~mL}$ of each supernatant was mixed vigorously with $4 \mathrm{~mL}$ Salkowski's reagent $\left(150 \mathrm{~mL}\right.$ of concentrated $\mathrm{H}_{2} \mathrm{SO}_{4}, 250 \mathrm{~mL}$ distilled $\mathrm{H}_{2} \mathrm{O}, 7.5 \mathrm{~mL} 0.5 \mathrm{M}$ $\mathrm{FeCl}_{3} \cdot 6 \mathrm{H}_{2} \mathrm{O}$ ). The reaction proceeded at room temperature for $20 \mathrm{~min}$ before the absorbance at $535 \mathrm{~nm}$ was measured. To quantify IAA production, absorbance at $535 \mathrm{~nm}$ was divided by the optical density at $600 \mathrm{~nm}$ to take into account the variability of culture growth.

\subsection{Pisum sativum Growth Experiments and GUS Staining}

DR5::GUSA pea plants were inoculated with bacteria or left uninoculated (sterile water only) 2 days after the seeds were planted in Magenta jars [66]. The seeds were sterilized in 50\% ethanol for $5 \mathrm{~min}$, in $10 \%$ commercial bleach for $10 \mathrm{~min}$, and rinsed 5-10 times with sterile water before planting. B. simplex was grown in liquid TY until stationary phase when the cells were harvested by centrifugation $(8000 \times \mathrm{g}, 10 \mathrm{~min})$, and the pellets washed with sterile water three times to remove the growth medium. The cell pellets were diluted to $\mathrm{OD}_{600}=0.2$ in $1 / 4$ strength Hoagland's N-free medium [67] or sterile water. For inoculation of pea, Rlv/pHC60 (Table 1) was used. This strain was constructed via a triparental mating using the plasmid pHC60, which carries GFP [68]. $2 \mathrm{~mL}$ of either B. simplex $30 \mathrm{~N}-5$ or Rlv/pHC60 were added to the Magenta jars. Coinoculated pea plants were inoculated with $1 \mathrm{~mL}$ B. simplex $30 \mathrm{~N}-5$ and $1 \mathrm{~mL}$ Rlv/pHC60. The uninoculated control peas were watered with $2 \mathrm{~mL}$ of sterile water or $1 / 4$ strength Hoagland's $\mathrm{N}$-free medium. Ten or more pea plants per treatment were set up per experiment, and the plants were harvested 14 dpi or later.

For GUS staining, plant roots were removed from the Magenta jars and washed to remove all perlite and vermiculite particles. Tissues were prepared as described by [69].

A pot growth experiment was done in the UCLA Plant Growth Center. After sterilization, P. sativum DR5::GUSA seeds were planted in pots containing a perlite/vermiculite mixture [66] topped with sterile beads to minimize contamination. B. simplex $30 \mathrm{~N}-5$, Rlv, and B. subtilis 30VD-1 were grown in liquid culture to a final cell density of $\mathrm{OD}_{600}=0.3-0.4$. At germination, the plants were inoculated with $1 \mathrm{~mL}$ of $B$. simplex $30 \mathrm{~N}-5$ or Rlv or $B$. subtilis $30 \mathrm{VD}-1$. Coinoculated pea plants were inoculated with $0.5 \mathrm{~mL} \mathrm{~B}$. simplex $30 \mathrm{~N}-5$ and $0.5 \mathrm{~mL}$ Rlv, or with $0.5 \mathrm{~mL} \mathrm{~B}$. subtilis $30 \mathrm{VD}-1$ and $0.5 \mathrm{~mL}$ Rlv. The uninoculated control peas were watered with $1 \mathrm{~mL}$ of sterile water or $1 / 4$ strength Hoagland's N-free medium. The plants were watered every 3-4 days with $150 \mathrm{~mL}$ of $1 / 4$ strength Hoagland's medium (with or without nitrogen) or with sterile water, and harvested 3 weeks post inoculation.

At varying times, plants were harvested and shoot and root length, lateral root number, nodule number (where appropriate), and dry biomass were measured.

\subsection{Nodules Squashes and Microscopy}

Pea roots were coinoculated as described. Fourteen dpi or later, root nodules were surface-sterilized in $10 \%$ bleach for $10 \mathrm{~min}$, washed with sterile water 10 times, and then squashed in $20 \mu \mathrm{L}$ of sterile 
water with a sterile glass rod. The nodule squashate was diluted 1:10, 1:100, and 1:1000. $20 \mu \mathrm{L}$ of each dilution was spread on TY agar. The plates were incubated at $30{ }^{\circ} \mathrm{C}$.

Roots and nodules were examined directly after staining with a Zeiss Axiophot Microscope. Nodules, either singly inoculated or coinoculated, were fixed in 4\% glutaraldehyde in $0.1 \mathrm{M}$ phosphate buffer ( $\mathrm{pH}$ 6.8) and embedded in methacrylate. Plastic-embedded material was sectioned for light microscopy at 3 or $4 \mu \mathrm{m}$, affixed to polylysine-coated slides, and stained with $1 \%$ aqueous acid fuchsin or as described in [51]. GUS-stained nodules were also embedded in methacrylate, sectioned as described, and counter-stained with safranin $\mathrm{O}$.

\subsection{Phosphate Solubilization Assay}

Pikovskaya phosphate medium (PVK) was made according to [70]. For inoculation onto plates, the bacterial strains were grown in liquid medium until stationary phase at which time the cells were harvested by centrifugation $(8000 \times g, 10 \mathrm{~min})$, and the pellets washed with sterile water three times to remove any traces of the medium. The cell pellets were diluted to $\mathrm{OD}_{600}=0.2$ in sterile water. $5 \mu \mathrm{L}$ droplets were spotted onto the plates and allowed to dry right side up for $20 \mathrm{~min}$. The plates were incubated upside down at $30{ }^{\circ} \mathrm{C}$ for 10 days and the size of the clearing zone around the colony was measured. The averages and standard deviations were calculated for ca. 20 colonies of Rlv, B. simplex, and B. subtilis. The experiment was repeated three times.

\subsection{Siderophore Assay}

CAS agar medium devoid of nutrients was used as an indicator of siderophore presence. The components needed for a liter of the overlay medium were: $0.5 \mathrm{M}$ MOPS buffer, $10 \mathrm{~g} \mathrm{MgSO}_{4} \cdot 7 \mathrm{H}_{2} \mathrm{O}$, $1 \mathrm{~g} \mathrm{CaCl}_{2} 2 \mathrm{H}_{2} \mathrm{O}, 50 \mathrm{~mL}$ of Solution I (Chrome Azurol S (CAS) $0.065 \mathrm{~g}$ in $50 \mathrm{~mL} \mathrm{H} \mathrm{H}_{2} \mathrm{O}$ ), $10 \mathrm{~mL}$ of Solution II $\left(0.135 \mathrm{~g} \mathrm{FeCl}_{3} 2 \mathrm{H}_{2} \mathrm{O}\right.$ in $\left.500 \mathrm{~mL} \mathrm{H} \mathrm{H}_{2} \mathrm{O}\right), 40 \mathrm{~mL}$ of Solution III $(0.0729 \mathrm{~g}$ CTAB in $40 \mathrm{~mL}$ $\mathrm{H}_{2} \mathrm{O}$ ) and $9 \mathrm{~g}$ Bacto-Agar [71]. $10 \mathrm{~mL}$ of the gel was spread as an overlay on culture plates of $B$. simplex on grown for 4 days on several solid media, including LB, TY, and BAP $+\mathrm{N}$ [58] medium, or over B. simplex and B. subtilis spotted onto TY plates. After a maximum period of 15 min, a color change in the blue medium was observed around the colonies. The experiment was repeated three times.

\subsection{Analysis of Anti-Fungal Activity}

B. simplex $30 \mathrm{~N}-5$ and the two $B$. subtilis strains were grown in liquid TY or LB. $1 \mathrm{~mL}$ of bacteria was transferred separately to autoclaved Eppendorf tubes and centrifuged at 14,000 rpm for $10 \mathrm{~min}$ at $22{ }^{\circ} \mathrm{C}$. The supernatant was discarded and the pellet was re-suspended in sufficient sterile water to dilute the bacteria to a final cell density of $\mathrm{OD}_{600}=0.3-0.4$.

$50 \mu \mathrm{L}$ of the bacterial suspension or sterile water were inoculated onto PDA, V8, or ISP2 [57] agar plates and incubated at $30{ }^{\circ} \mathrm{C}$. After 0 (B. subtilis $\left.30 \mathrm{VD}-1\right)$ or $24 \mathrm{~h}$ (B. simplex $30 \mathrm{~N}-5$ and B. subtilis BAL218) of incubation at $30{ }^{\circ} \mathrm{C}$, fungal plugs were placed $2.5 \mathrm{~cm}$ away from the site of bacterial inoculation. Measurements of fungal radial growth with a ruler were taken every $24 \mathrm{~h}$ using a dissecting microscope or a Quebec ${ }^{\circledR}$ Dark-Field Colony counter. The percentage of growth inhibition 
was calculated using the equation: $\%$ growth inhibition $=F_{C}-F_{B S} / F_{C}$ where $F_{C}=$ Fungus control and $\mathrm{F}_{\mathrm{BS}}=$ Fungus inoculated with $B$. simplex or B. subtilis [72]. Photos were taken with Olympus digital camera FE-370. Graphs illustrating fungal radial growth were done in Excel and standard errors were calculated.

\section{Conclusions}

Taken together, the data presented herein strongly suggest that B. simplex $30 \mathrm{~N}-5$ is an effective PGPB on legumes and operates via a mechanism that involves fungal antagonism, phosphate solubilization, siderophore production, and auxin secretion. However, we cannot conclude whether the source of IAA triggering the expression of the DR5::GUS construct is exclusively from $B$. simplex $30 \mathrm{~N}-5$. The possibility exists that auxin synthesized by the plant is also involved. For example, although auxin-induced GUS staining was detected in Arabidopsis in response to Phyllobacterium brassicacearum inoculation, this PGPB strain produced very low levels of IAA and did not cause an increase in IAA content in plant roots [73]. By employing Arabidopsis lines mutated in IAA production, transport, or signaling, these authors determined that $P$. brassicacearum inoculation stimulated auxin production by the plant. Additional experiments will be needed to determine whether IAA synthesis is similarly up-regulated in legumes upon PGPB inoculation.

We also conclude that B. subtilis 30VD-1 has the potential of being an effective biocontrol agent against Fusarium, but additional tests on plants are required. A multi-species consortium of nodulating and growth-promoting bacteria is proposed as a better way to inoculate legume crops for growth improvement in poor soils.

\section{Acknowledgments}

We thank the following UCLA undergraduate students for their assistance in the project: Brittany Yee, Faith Oh, Diane Kim, Emily Chan, Sophie Hung, Rudolf Benitez, Nigar Yusifova, Christine Kim, Ethan Mathews, Maryam Motamedinia, Archie McCoy, Han S. Kim, Walter Kim, Judy Wong, Meghrik Assadourian, Joanne Fortier, Stephen Tran, Andrew Wang, Marie-Claire Matsuo, Manpreet Sekhon, and Huang Vuong. We acknowledge Drs. Martha C. Hawes (University of Arizona), H. Corby Kistler (University Minnesota-St. Paul), Beth A. Lazazzera (University of California, Los Angeles), Kerry O’Donnell (ARS/University of California, Los Angeles, Peoria, IL, USA), and Paul H. Williams (University of Wisconsin-Madison) for bacterial and fungal strains. John Regus and Matthew O’Neill (University of California-Riverside) are thanked for sectioning nodules.

We received financial support from the Shanbrom Family Foundation and from UCLA's Molecular, Cell and Developmental Biology Department. The research courses were supported in part by a grant to the University of California, Los Angeles (No. 52006944), from the Howard Hughes Medical Institute through the Precollege and Undergraduate Science Education Program. The UCLA Office of Instructional Development (IIP \#10-18) also provided support for this project. Nancy A. Fujishige was funded in part by NSF-IOS0747517. William Villella and Janahan Vijanderan were supported in part by NSF-DUE grant 1022918, and Irma Ortiz by NIH grant GM55052 to Richard L. Weiss (University of California, Los Angeles) and by NSF1137471 (PLANTS) to present her work at a 
Botanical Society of America meeting. We thank Kris Reddi (University of California, Los Angeles) for preparing the DNA for genome sequencing, and the UCLA Genotyping and Sequencing Core (Genoseq, Los Angeles, CA, USA) for 454 pyrosequencing of the B. simplex genome.

Special thanks are extended to Stefan J. Kirchanski for his comments on the manuscript.

\section{Conflicts of Interest}

The authors declare no conflict of interest.

\section{References}

1. Bashan, Y.; Holguin, G. Proposal for the division of plant growth-promoting rhizobacteria into two classifications: Biocontrol-PGPB (plant growth-promoting bacteria) and PGPB. Soil Biol. Biochem. 1998, 30, 1225-1228.

2. Lugtenberg, B.; Kamilova, F. Plant-growth-promoting rhizobacteria. Ann. Rev. Microbiol. 2009, 63, 541-556.

3. Ortíz-Castro, R.; Contreras-Cornejo, H.A.; Macías-Rodríguez, L.; López-Bucio, J. The role of microbial signals in plant growth and development. Plant Signal. Behav. 2009, 4, 701-712.

4. Glick, B.R. Using soil bacteria to facilitate phytoremediation. Biotechnol. Adv. 2010, 28, 367-374.

5. Fravel, D. Commercialization and implementation of biocontrol. Ann. Re. Phytopathol. 2005, 43, $337-359$.

6. Zhang, H.; Kim, M.-S.; Sun, Y.; Dowd, S.E.; Shi, H.; Paré, P.W. Soil bacteria confer plant salt tolerance by tissue-specific regulation of the sodium transporter HKT1. Mol. Plant-Microbe Interact. 2008, 21, 737-744.

7. Zhang, H.; Murzello, C.; Sun, Y.; Kim, M.-S.; Xie, X.; Jeter, R.M.; Zak, J.C.; Dowd, S.E.; Paré, P.W. Choline and osmotic-stress tolerance induced in Arabidopsis by the soil microbe Bacillus subtilis (GB03). Mol. Plant-Microbe Interact. 2010, 23, 1097-1104.

8. Zhang, J.; Howell, C.; Starr, J. Suppression of Fusarium colonization of cotton roots and Fusarium wilt by seed treatments with Gliocladium virens and Bacillus subtilis. Biocontrol Sci. Technol. 1996, 6, 175-188.

9. Idris, E.E.; Iglesias, D.J.; Talon, M.; Borriss, R. Tryptophan-dependent production of indole-3-acetic acid (IAA) affects level of plant growth promotion by Bacillus amyloliquefaciens FZB42. Mol. Plant-Microbe Interact. 2007, 20, 619-626.

10. Benhamou, N.; Kloepper, J.W.; Quadt-Hallman, A.; Tuzun, S. Induction of defense-related ultrastructural modifications in pea root tissues inoculated with endophytic bacteria. Plant Physiol. 1996, 112, 919-929.

11. Probanza, A.; Mateos, J.; García, J.L.; Ramos, B.; de Felipe, M.; Mañero, F.G. Effects of inoculation with PGPR Bacillus and Pisolithus tinctorius on Pinus pinea 1. Growth, bacterial rhizosphere colonization, and mycorrhizal infection. Microbial. Ecol. 2001, 41, 140-148.

12. Bai, Y.M.; Zhou, X.M.; Smith, D.L. Enhanced soybean plant growth resulting from coinoculation of Bacillus strains with Bradyrhizobium japonicum. Crop Sci. 2003, 43, 1774-1781. 
13. Handelsman, J.; Raffel, S.; Mester, E.H.; Wunderlich, L.; Grau, C.R. Biological control of damping-off of alfalfa seedlings with Bacillus-cereus UW85. Applied and Environmental Microbiology 1990, 56, 713-718.

14. López-Bucio, J.; Campos-Cuevas, J.C.; Hernández-Calderón, E.; Velásquez-Becerra, C.; Farías-Rodríguez, R.; Macías-Rodríguez, L.I.; Valencia-Cantero, E. Bacillus megaterium rhizobacteria promote growth and alter root-system architecture through an auxin-and ethylene-independent signaling mechanism in Arabidopsis thaliana. Mol. Plant-Microbe Interact. 2007, 20, 207-217.

15. Francis, I.; Holsters, M.; Vereecke, D. The Gram-positive side of plant-microbe interactions. Environ. Microbiol. 2010, 12, 1-12.

16. Berg, G. Plant-microbe interactions promoting plant growth and health: Perspectives for controlled use of microorganisms in agriculture. Appl. Microbiol. Biotechnol. 2009, 84, 11-18.

17. Choudhary, D.K.; Johri, B.N. Interactions of Bacillus spp. and plants-With SPECIAL reference to induced systemic resistance (ISR). Microbiol. Res. 2009, 164, 493-513.

18. Rajkumar, M.; Ma, Y.; Freitas, H. Characterization of metal-resistant plant-growth promoting Bacillus weihenstephanensis isolated from serpentine soil in Portugal. J. Basic Microbiol. 2008, 48, 500-508.

19. Gutiérrez-Luna, F.M.; López-Bucio, J.; Altamirano-Hernández, J.; Valencia-Cantero, E.; de la Cruz, H.R.; Macías-Rodríguez, L. Plant growth-promoting rhizobacteria modulate root-system architecture in Arabidopsis thaliana through volatile organic compound emission. Symbiosis 2010, 51, 75-83.

20. Lamsal, K.; Kim, S.W.; Kim, Y.S.; Lee, Y.S. Application of rhizobacteria for plant growth promotion effect and biocontrol of anthracnose caused by Colletotrichum acutatum on pepper. Mycobiology 2012, 40, 244-251.

21. Ryu, C.-M.; Farag, M.A.; Hu, C.-H.; Reddy, M.S.; Wei, H.-X.; Paré, P.W.; Kloepper, J.W. Bacterial volatiles promote growth in Arabidopsis. Proc. Natl. Acad. Sci. USA 2003, 100, 4927-4932.

22. Rashid, S.; Charles, T.C.; Glick, B.R. Isolation and characterization of new plant growth-promoting bacterial endophytes. Appl. Soil Ecol. 2012, 61, 217-224.

23. Guiñazú, L.B.; Andrés, J.A.; Del Papa, M.F.; Pistorio, M.; Rosas, S.B. Response of alfalfa (Medicago sativa L.) to single and mixed inoculation with phosphate-solubilizing bacteria and Sinorhizobium meliloti. Biol. Fertil. Soils 2010, 46, 185-190.

24. Rojas, A.; Holguin, G.; Glick, B.R.; Bashan, Y. Synergism between Phyllobacterium sp. ( $\mathrm{N}_{2}$-fixer) and Bacillus licheniformis (P-solubilizer), both from a semiarid mangrove rhizosphere. FEMS Microbiol. Ecol. 2001, 35, 181-187.

25. Vivas, A.; Marulanda, A.; Ruiz-Lozano, J.M.; Barea, J.M.; Azcón, R. Influence of a Bacillus sp. on physiological activities of two arbuscular mycorrhizal fungi and on plant responses to PEG-induced drought stress. Mycorrhiza 2003, 13, 249-256.

26. Bacon, C.W.; Yates, I.E.; Hinton, D.M.; Meredith, F. Biological control of Fusarium moniliforme in maize. Environ. Health Perspect. 2001, 109, 325-332. 
27. Zhang, Y.Z.; Chen, W.F.; Li, M.; Sui, X.H.; Liu, H.-C.; Zhang, X.X.; Chen, W.X. Bacillus endoradicis sp. nov., an endophytic bacterium isolated from soybean root. Int. J. Syst. Evol. Microbiol. 2012, 62, 359-363.

28. Erturk, Y.; Ercisli, S.; Haznedar, A.; Cakmakci, R. Effects of plant growth promoting rhizobacteria (PGPR) on rooting and root growth of kiwifruit (Actinidia deliciosa) stem cuttings. Biol. Res. 2010, 43, 91-98.

29. Hassen, A.I.; Labuschagne, N. Root colonization and growth enhancement in wheat and tomato by rhizobacteria isolated from the rhizoplane of grasses. World J. Microbiol. Biotechnol. 2010, 26, 1837-1846.

30. Ash, C.; Farrow, J.A.E.; Wallbanks, S.; Collins, M.D. Phylogenetic heterogeneity of the genus Bacillus revealed by comparative-analysis of small-subunit-ribosomal RNA sequences. Lett. Appl. Microbiol. 1991, 13, 202-206.

31. Koeppel, A.; Perry, E.B.; Sikorski, J.; Krizanc, D.; Warner, A.; Ward, D.M.; Rooney, A.P.; Brambilla, E.; Connor, N.; Ratcliff, R.M. Identifying the fundamental units of bacterial diversity: A paradigm shift to incorporate ecology into bacterial systematics. Proc. Natl. Acad. Sci. USA 2008, 105, 2504-2509.

32. Xu, D.; Côte, J.-C. Phylogenetic relationships between Bacillus species and related genera inferred from comparison of $3^{\prime}$ end 16S rDNA and $5^{\prime}$ end 16S-23S ITS nucleotide sequences. Int. J. Syst. Evol. Microbiol. 2003, 53, 695-704.

33. Petersen, D.J.; Srinivasan, M.; Chanway, C.P. Bacillus polymyxa stimulates increased Rhizobium etli populations and nodulation when co-resident in the rhizosphere of Phaseolus vulgaris. FEMS Microbiol. Lett. 1996, 142, 271-276.

34. Srinivasan, M.; Holl, F.; Petersen, D. Nodulation of Phaseolus vulgaris by Rhizobium etli is enhanced by the presence of Bacillus. Can. J. Microbiol. 1997, 43, 1-8.

35. Turner, J.; Backman, P. Factors relating to peanut yield increases after seed treatment with Bacillus subtilis. Plant Dis. 1991, 75, 347-353.

36. Rajendran, G.; Sing, F.; Desai, A.J.; Archana, G. Enhanced growth and nodulation of pigeon pea by co-inoculation of Bacillus strains with Rhizobium spp. Bioresour. Technol. 2008, 99, 4544-4550.

37. Halverson, L.J.; Handelsman, J. Enhancement of soybean nodulation by Bacillus cereus UW85 in the field and in a growth chamber. Appl. Environ. Microbiol. 1991, 57, 2767-2770.

38. Hirsch, A.M. Developmental biology of legume nodulation. New Phytologist 1992, 122, 211-237.

39. DeMason, D.A.; Polowick, P.L. Patterns of DR5::GUS expression in organs of pea (Pisum sativum). Int. J. Plant Sci. 2009, 170, 1-11.

40. Sikorski, J.; Nevo, E. Adaptation and incipient sympatric speciation of Bacillus simplex under microclimatic contrast at "Evolution Canyons" I and II, Israel. Proc. Natl. Acad. Sci. USA 2005, 102,15924-15929.

41. Ding, Y.; Wang, J.; Liu, Y.; Chen, S. Isolation and identification of nitrogen-fixing Bacilli from plant rhizospheres in Beijing region. J. Appl. Microbiol. 2005, 99, 1271-1281.

42. Liu, X.; Zhao, H.; Chen, S. Colonization of maize and rice plants by strain Bacillus megaterium C4. Curr. Microbiol. 2006, 52, 186-190. 
43. Xie, G.H.; Cui, Z.; Yu, J.; Yan, J.; Hai, W.; Steinberger, Y. Identification of nif genes in $\mathrm{N}_{2}$-fixing bacterial strains isolated from rice fields along the Yangtze river plain. J. Basic Microbiol. 2006, 46, 56-63.

44. Achouak, W.; Normand, P.; Heulin, T. Comparative phylogeny of rrs and nifH genes in the Bacillaceae. Int. J. Syst. Microbiol. 1999, 49, 961-967.

45. Penrose, D.M.; Glick, B.R. Methods for isolating and characterizing ACC deaminase-containing plant growth-promoting rhizobacteria. Physiol. Plant. 2003, 118, 10-15.

46. Kistler, H.C.; Bosland, P.W.; Benny, U.; Leong, S.; Williams, P. Relatedness of strains of Fusarium oxysporum from crucifers measured by examination of mitochondrial and ribosomal DNA. Phytopathology 1987, 77, 1289-1293.

47. O’Donnell, K.; Gueidan, C.; Sink, S.; Johnston, P.R.; Crous, P.W.; Glenn, A.; Riley, R.; Zitomer, N.C.; Colyer, P.; Waalwijk, C. A two-locus DNA sequence database for typing plant and human pathogens within the Fusarium oxysporum species complex. Fungal Genet. Biol. 2009, 46, 936-948.

48. Sun, Y.; Cheng, Z.; Glick, B.R. The presence of a 1-aminocyclopropane-1-carboxylate (ACC) deaminase deletion mutation alters the physiology of the endophytic plant growth-promoting bacterium Burkholderia phytofirmans PsJN. FEMS Microbiol. Lett. 2009, 296, 131-136.

49. Paz, I.; Santin, R.; Guimarães, A.; Rosa, O.; Dias, A.; Quecine, M.; Azevedo, J.; Matsumura, A. Eucalyptus growth promotion by endophytic Bacillus spp. Genet. Mol. Res. 2012, 11, 3711-3720.

50. Guinel, F.C. Getting around the legume nodule: I. The structure of the peripheral zone in four nodule types. Botany-Botanique 2009, 87, 1117-1138.

51. Schwartz, D.; Munger, R.; Lazzaro, B.; Lumb, G. A modified Brown and Hopps stain for identification of Gram-positive and Gram-negative microorganisms in glycol methacrylate-embedded tissues. Arch. Pathol. Lab. Med. 1989, 113, 181-183.

52. Patten, C.L.; Glick, B.R. Role of Pseudomonas putida indoleacetic acid in development of the host plant root system. Appl. Environ. Microbiol. 2002, 68, 3795-3801.

53. Bianco, C.; Defez, R. Improvement of phosphate solubilization and Medicago plant yield by an indole-3-acetic acid-overproducing strain of Sinorhizobium meliloti. Appl. Environ. Microbiol. 2010, 76, 4626-4632.

54. Imperlini, E.; Bianco, C.; Lonardo, E.; Camerini, S.; Cermola, M.; Moschetti, G.; Defez, R. Effects of indole-3-acetic acid on Sinorhizobium meliloti survival and on symbiotic nitrogen fixation and stem dry weight production. Appl. Microbiol. Biotechnol. 2009, 83, 727-738.

55. Kloepper, J.W.; Leong, J.; Teintze, M.; Schroth, M.N. Enhanced plant growth by siderophores produced by plant growth-promoting rhizobacteria. Nature 1980, 286, 885-886.

56. Miller, P.M. V-8 juice agar as a general purpose medium for fungi and bacteria. Phytopathology 1955, 45, 461-462.

57. Atlas, R. Alphabetical Listing of Media. In Handbook of Microbiological Media; CRC Press: Boca Raton, FL, USA, 1993; pp. 455-462.

58. Tzean, S.; Torrey, J.G. Spore germination and the life cycle of Frankia in vitro. Can. J. Microbiol. 1989, 35, 801-806. 
59. Davis, K.E.R.; Joseph, S.J.; Janssen, P.H. Effects of growth medium, inoculum size, and incubation time on culturability and isolation of soil bacteria. Appl. Environ. Microbiol. 2005, 71, 826-834.

60. Miller, J.H. Experiments in Molecular Genetics; Cold Spring Harbor Laboratory: Cold Spring Harbor, NY, USA, 1972; p. 433.

61. Beringer, J.E. R-factor transfer in Rhizobium legumunosarum. J. Gen. Microbiol. 1974, 84, 188-198.

62. Vincent, J.M. A Manual for the Practical Study of the Root-Nodule Bacteria, IBP Handbook No. 15; Blackwell: Oxford and Edinburgh, UK, 1970; p. 6.

63. Weisburg, W.G.; Barns, S.M.; Pelletier, D.A.; Lane, D.J. 16S ribosomal DNA amplification for phylogenetic study. J. Bact. 1991, 173, 697-703.

64. Altschul, S.F.; Gish, W.; Miller, W.; Myers, E.W.; Lipman, D.J. Basic local alignment search tool. J. Mol. Biol. 1990, 215, 403-410.

65. Tamura, K.; Peterson, D.; Peterson, N.; Stecher, G.; Nei, M.; Kumar, S. MEGA5: Molecular evolutionary genetics analysis using maximum likelihood, evolutionary distance, and maximum parsimony methods. Mol. Biol. Evolution. 2011, 28, 2731-2739.

66. Angus, A.A.; Lee, A.S.; Lum, M.R.; Shehayeb, M.; Hessabi, R.; Fujishige, N.A.; Yerrapragada, S.; Kano, S.; Song, N.; Yang, P.; et al. Nodulation and effective nitrogen fixation of Macroptilium atropurpureum (siratro) by Burkholderia tuberum, a beta-proteobacterium, are influenced by environmental factors. Plant Soil 2013, 362, 543-562.

67. Machlis, L.; Torrey, J.G. Plants in Action: A Laboratory Manual of Plant Physiology; W.H. Freeman and Company: San Francisco, CA, USA, 1956; p. 44.

68. Cheng, H.P.; Walker, G.C. Succinoglycan is required for initiation and elongation of infection threads during nodulation of alfalfa by Rhizobium meliloti. J. Bacteriol. 1998, 180, 5183-5191.

69. Jefferson, R. The GUS reporter gene system. Nature 1989, 342, 837-838.

70. Pikovskaya, R. Mobilization of phosphorus in soil in connection with vital activity of some microbial species. Mikrobiologiya 1948, 17, 362-370.

71. Pérez-Miranda, S.; Cabirol, N.; George-Téllez, R.; Zamudio-Rivera, L.; Fernández, F. O-CAS, a fast and universal method for siderophore detection. J. Microbiol. Methods 2007, 70, 127-131.

72. Schmidt, S.; Blom, J.F.; Pernthaler, J.; Berg, G.; Baldwin, A.; Mahenthiralingam, E.; Eberl, L. Production of the antifungal compound pyrrolnitrin is quorum sensing-regulated in members of the Burkholderia cepacia complex. Environ. Microbiol. 2009, 11, 1422-1437.

73. Contesto, C.; Milesi, S.; Mantelin, S.; Zancarini, A.; Desbrosses, G.; Varoquaux, F.; Bellini, C.; Kowalczyk, M.; Touraine, B. The auxin-signaling pathway is required for the lateral root response of Arabidopsis to the rhizobacterium. Phyllobacterium brassicacearum Planta 2010, 232, $1455-1470$. 


\section{Appendix}

Figure A1. Colorimetric detection of auxin production from culture medium supplemented with L-tryptophan. The amounts indicated $(\mu \mathrm{g} / \mathrm{mL})$ of tryptophan were added to each culture. The bacteria were grown as described in the Materials and Methods, and the growth medium was collected for analysis. Each data point represents 7 independent samples. Auxin bound to iron is detected at $\mathrm{OD}_{535}$, and that value is divided by the bacterial concentration detected at $\mathrm{OD}_{600}$. The slope of the line was calculated by the equation: $Y=0.0793 X+0.0478, R^{2}=0.9696$, and the standard deviations are indicated.

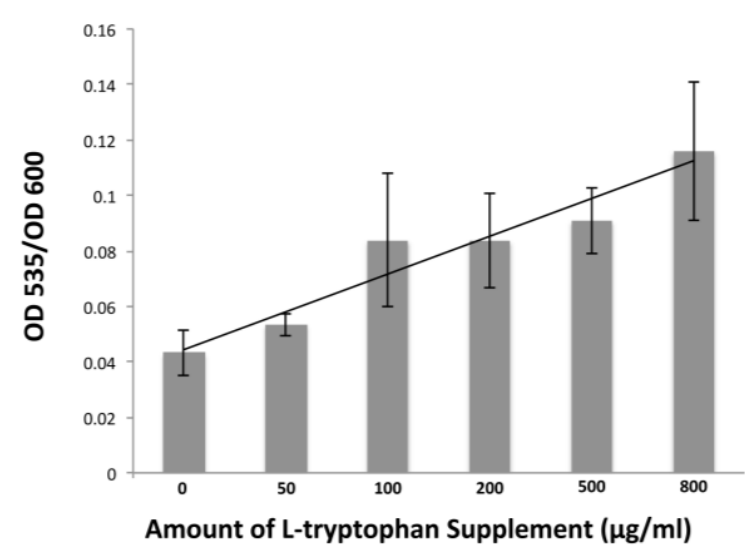

Figure A2. Iron-binding (A-C) and phosphate solubilization assays; (A) B. simplex grown on LB with Chrome Azurol S overlay; (B) Similar to A, but TY medium was used, the black arrows indicate $B$. simplex whereas the white arrows indicate B. subtilis BAL218, the halos indicate siderophore production; (C) CAS assay for B. subtilis 30VD-1; (D) B. subtilis $30 \mathrm{VD}-1$ is able to degrade rock phosphate; The arrow delimits the edge of the phosphate-solubilization zone.

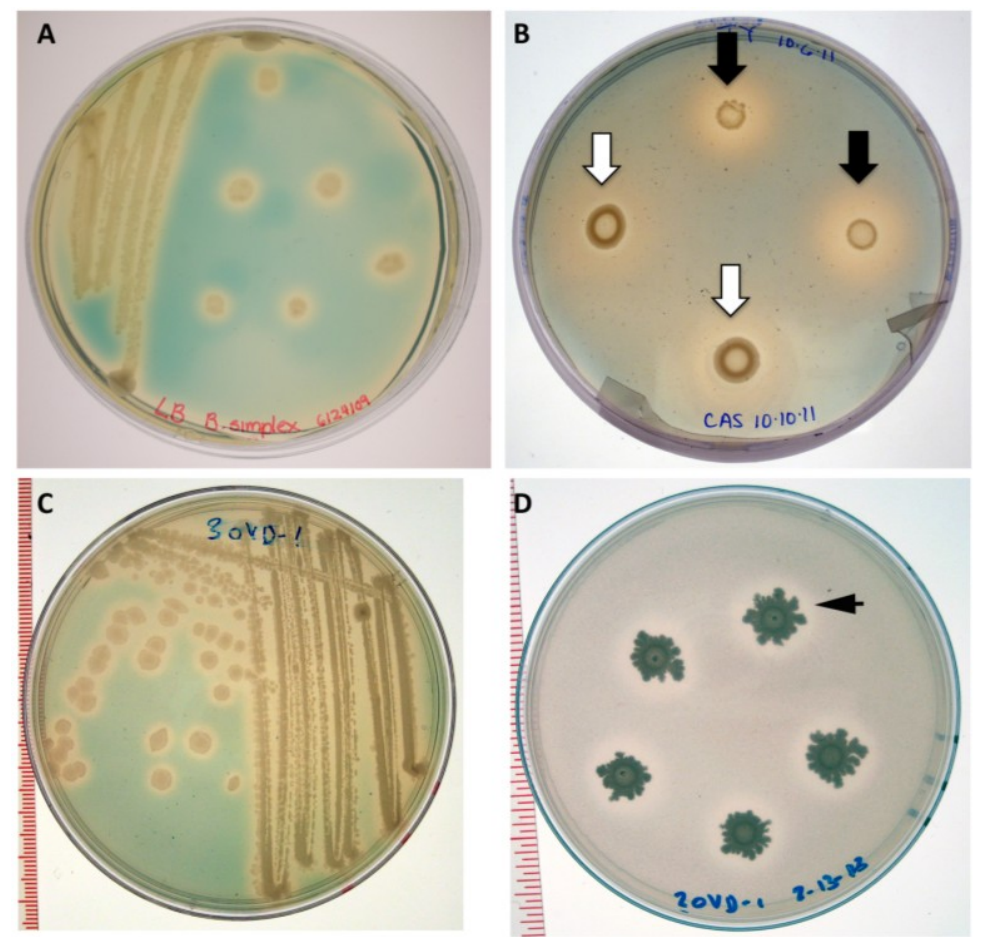


Table A1. PCR primers and conditions used in this study.

\begin{tabular}{|c|c|c|c|c|}
\hline Gene & Sequence & $\begin{array}{c}\text { PCR } \\
\text { Conditions }\end{array}$ & $\begin{array}{l}\text { Size } \\
\text { (bp) }\end{array}$ & Reference \\
\hline $\begin{array}{l}16 \mathrm{~S} \\
\text { rRNA }\end{array}$ & $\begin{array}{l}\text { 5'-CCGAATTCGTCGACAACAGAGTTTGATCCTGGCTCAG-3' } \\
\text { 5'-CCCGGGATCCAAGCTTAAGGAGGTGATCCAGCC-3' }\end{array}$ & $\begin{array}{c}5 \mathrm{~min} \text { at } 95^{\circ} \mathrm{C}, \\
30 \text { cycles of } 30 \mathrm{~s} \text { at } 94{ }^{\circ} \mathrm{C}, \\
30 \mathrm{~s} \text { at } 55^{\circ} \mathrm{C}, \\
1.5 \mathrm{~min} \text { at } 68^{\circ} \mathrm{C}, \\
\text { and } 10 \mathrm{~min} \text { at } 68^{\circ} \mathrm{C}\end{array}$ & 832 & {$[64]$} \\
\hline nifH & $\begin{array}{l}\text { 5'-CTGVGCCTTGTTYTCGCGGGATSGGCATGGC-3' } \\
\text { 5'-GGCTGCGATCCVAAGGCCGAYTCVACCCG-3', }\end{array}$ & same as above & $\begin{array}{l}\text { ca. } \\
300\end{array}$ & {$[42]$} \\
\hline$a c d S$ & $\begin{array}{l}\text { 5'-TACAAAGCTTATGAACCTGCAACGATTCC-3' } \\
\text { 5'-AATGGATCCTTAGCCGTTGCGGAAAAATG-3 }\end{array}$ & same as above & 1017 & [49] \\
\hline
\end{tabular}

(C) 2013 by the authors; licensee MDPI, Basel, Switzerland. This article is an open access article distributed under the terms and conditions of the Creative Commons Attribution license (http://creativecommons.org/Licenses/by/3.0/). 